\section{Wage Rates and Job Queues}

Does the Public Sector Overpay in Ethiopia?

Taye Mengistae
Analysis of recent household

survey data from Ethiopia

suggests a huge public sector pay premium. This seems to have contributed to the creation of a large queue for public sector jobs.

The World Bank

Development Research Group April 1999 
Policy Research Working Paper 2105

\section{Summary findings}

The public sector's share in wage employment is higher in Africa - including Ethiopia's urban labor market than in developed economies. Fuller unionization, greater job security, and more generous nonwage benefits in the public sector lead one to assume that workers might queue up for public sector jobs. Do higher wage rates in Ethiopia's public sector create such a queue?

Mengistae extends Lee's two-stage structural probit analysis to test (with data from a recent urban household survey) and measure the existence and scope of such a queue for public sector jobs in Ethiopia.

The results reject the absence of job rationing in favor of an implicit queue of most private sector workers for public sector jobs. The queue exists mainly because of popular expectations of a wage premium (between 11 and 40 percent) in the public sector.

Controlling for individual differences in expectations of the sectoral wage differences, Mengistae finds that skill does not significantly affect a worker's sector preferences, but some social characteristics do.
A worker with a traditional farming background is more likely to be in the queue than is a secondgeneration urban dweller. This is interesting, considering that the influx of rural migrants to urban centers in the last few decades has been partly fueled by hopes of public sector employment.

On average, women are more likely than men, and workers in provincial towns more likely than workers in the capital, to prefer public sector jobs

Level of schooling and job experience do not seem to affect preferences for the public over the private sector.

The probability of a worker's being selected from the public sector job queue decreases with the wage rate the worker potentially commands as a public sector employee. Workers on the lower end of the pay scale are more likely to be selected.

Among workers who join the queue for public sector jobs, men are more likely to be hired than women and skilled workers are more likely to be hired than lessskilled workers.

This paper - a product of the Development Research Group - is part of a larger effort in the group to understand the link between public sector employment and the performance of the labor market. Copies of the paper are available free from the World Bank, 1818 H Street NW, Washington, DC 20433. Please contact Anna Regina Bonfield, room MC3-354, telephone 202-473-1248, fax 202-522-3518, Internet address abonfield@worldbank.org. Policy Research Working Papers are also posted on the Web at http://www.worldbank.org/html/dec/Publications/Workpapers/home.html. The author may be contacted at tmengistae@worldbankd.org April 1999 (40 pages).

The Policy Research Working Paper Series disseminates the findings of work in progress to encourage the exchange of ideas about development issues. An objective of the series is to get the findings out quickly, even if the presentations are less than fully polished. The papers carry the names of the authors and should be cited accordingly. The findings, interpretations, and conclusions expressed in this paper are entirely those of the authors. They do not necessarily represent the view of the World Bank, its Executive Directors, or the countries they represent. 


\title{
Wage Rates and Job Queues: Does the Public Sector Overpay in Ethiopia?
}

\author{
Taye Mengistae \\ The World Bank \\ Key words: wage differentials, segmented labour markets, Ethiopia \\ JEL classification numbers: C34, J31, J42, J45.
}

\section{Introduction}

The urban labour market in Ethiopia is typical of those in Africa and many other least developed countries in that the share of the public sector in wage employment is very high compared to that found in developed economies. ${ }^{1}$ Greater degree of unionisation, greater job security and what appears to be a more generous provision of non-wage benefits in the public sector are among the factors suggesting that at least some private workers may be implicitly queuing up for public sector jobs in the sense of preferring public sector employment to their current status. The main objective of this paper is to test whether or not such a queue does indeed exist in the country and to measure the contribution of sectoral wage differentials in generating or precluding it. Are public sector wage rates competitive enough to support a private sector wage premium as a counterbalance to the tendency of non-wage attractions of public sector employment to produce a queue? Or, do higher public sector wages in fact contribute to the creation of a queue? This is an important policy question which, apart from having a fiscal implication, could bear on

\footnotetext{
${ }^{1}$ Over the period 1979-80, for instance, the public sector employed about a third of the non-agricultural labour force in Africa compared to a corresponding figure of under ten per cent in OECD countries (Heller and Tait, 1984).
} 
the influence of public sector pay policy on unemployment. ${ }^{2}$ In order to answer it I shall extend Lee's two-stage structural probit analysis (Lee, 1979) into a framework for testing and measuring the existence and scope of a job queue. Lee's basic method is based on a univariate sorting probit in the sectoral allocation of workers and has been widely applied in assessing the effect of earning differentials in the distribution of individual's between union and non-union jobs (e.g., Lee, 1978), between self-employment and wage employment (e.g., Rees and Shah, 1986) and between the public and private sectors (e.g., Hartog and Oosterbeek, 1993) ${ }^{3}$. However, an underlying assumption of the method is that, given any one of the three pairs of alternatives, a worker is always found in the sector where expected utility is higher. As pointed out by Abowd and Farber (1982), this will be the case only if the labour market being investigated clears. If there is excess demand for jobs in one of the sectors, the observed employment status of a worker depends on employers' job rationing rules as well as the worker's sector preference. A univariate criterion probit cannot, therefore, be given structural interpretation in terms of employee taste' alone in this case. The dependent variable of the indicator probit is a product of two others only one of which registers worker preferences. The other indicates whether or not a given worker satisfies the recruitment criteria of employers in the job rationing sector. It follows that, should a worker be found outside of the latter, it is not necessarily the case that he or she prefers the other sector. That the same worker is already in the preferred sector is, of course, a possibility. But it is also possible that he or she has been rationed out of it.

A suggested way out of this difficulty is to incorporate the recruitment criteria of employers into the value function of workers by assuming that individuals have full information on these criteria and take them into account in deciding whether or not to queue for rationed jobs. ${ }^{4}$ This would effectively merge the criterion functions of workers and employers into one. At the same

\footnotetext{
${ }^{2}$ See Stevenson (1992) for a discussion of the fiscal and growth implications of public sector pay and employement policy in a developing country context. Lindauer (1991) sets out conditions under which public sectror wage premiums may lead to a higher rate of open unemployment.

${ }^{3}$ Other studies of public- versus- private sector wage differentials in developed economies and based on the Heckman-Lee procedure of adjusting for selectivity bias are Shapiro and Stelcner (1989) for Canada, Van Ophem (1991) for the Netherlands, Hundley (1991) and Choudhury (1994) for the USA and Dustman and Van Soest (1995) for Germany.

${ }^{4}$ See, for example, Lee (1978) and Van der Gaag and Vijverberg (1988).
} 
time it would allow us to interpret the resulting univariate sorting probit as an expression of a utility maximising labour supply decision. 'The trouble with this approach is that, in the present context, 'queuing up' is not a costly decision but a state of preference. ${ }^{5}$ The only acceptable way in which a univariate criterion function can be interpreted as an expression of worker preferences seems, therefore, to assume away a job queue. However, this is an extreme restriction on the model, being no more justified a priori than the other extreme of a universal queue for rationed jobs.

One way of avoiding either of these restrictions is to replace the univariate criterion probit of Lee's basic model by Poirier's (1980) bivariate probit with partial observability. Apart from providing a basis for testing the existence and coverage of a job queue, this enables us to consistently estimate the proportion of workers whose choice of sector is constrained. The proportion is a useful indicator of the degree of job rationing in the market of interest. That we can estimate it at all is remarkable since the preference of workers outside of the job rationing sector is not observable. Although the idea of an endogenous switching model based on Poirier's probit is not new, this is the first attempt at its implementation as an extension of Lee's two-stage structural probit analysis. ${ }^{6}$ The two-stage probit analysis employed here yields less efficient parameter estimates than the single step maximum likelihood

\footnotetext{
${ }^{5} \mathrm{An}$ example of situations in which 'queuing up' is a costly option is the case of an unemployed worker faced with the choice between immediately taking up a job in sector $\mathrm{A}$ and remaining umemployed as a strategy for enhancing the prospect of getting a job in a preferred sector B in the future. Here, the probability of actually getting a job in B at any given date is part of the information the worker needs to determine the certainity equivalent of the net gain from joining the queue for jobs in sector B. However, this clearly is not the case of a worker who, for example, is employed in a non-union job but would rather be in a unionised job. A worker's desire for a union job or the lack of it does depend on the attributes of union and non-union jobs including a possible union wage premium. However, it should have no more to do with the worker's perceived chance of being selected by union employers than a consumer's preference ordering over a range of goods has to do with his or her means.

${ }^{6}$ The idea was first raised by Abowd and Farber (1982) and subsequently implemented by Venti (1988), to model the allocation of US workers between the private sector and federal employment. Heywood and Mohanty (1994) estimate reduced form parameters of a federal job queue in the US, but stop short of obtaining structural parameter estimates and do not, consequently, assess the role of wage differentials in generating or precluding a queue. Kreuger (1988) presents evidence that preference for federal jobs in the US depends largely on expected wage premiums without, however, estimating a sectoral allocation model.
} 
estimation of the same model as is done in Venti (1988). However, it is also far easier to implement unless we have recourse to highly restrictive assumptions of the kind used by Venti. These include the assumptions that rationed jobs are life time jobs and that human capital variables are correlated with sector preferences entirely through their effects on earning potential.

Previous studies of the role of pay differentials in the allocation of workers between the public and private sectors of economies with a state of development similar to that of Ethiopia include, Lindauer and Sabot (1983) on Tanzania, Van der Gaag and Vijverberg (1988) on Cote d'Ivoire and Terrel (1993) on Haiti. The first of these suffers from its failure to deal with the sample selection problem that arises in the estimation of sectoral wage differentials. The second is an application of the univariate structural probit method and is, therefore, subject to this paper's criticism of a univariate specification of the switch between sectoral wage regimes. The third study does not depend on the estimation a structural switching function. However, it is based on the estimation of conditional wage functions the selectivity terms of which imply a univariate probit specification of the switch between public sector and private sector employment. As pointed out in Poirier (1980) and Farber (1983), the misspecification of a bivariate probit switching equation as a simple probit creates an omitted-variable problem in the estimation of the conditional wage functions.

The paper is organised as follows. The model, its estimation and test procedures are discussed in Section 2. Empirical Results are reported in Section 3. Section 4 is summary and conclusion.

\section{The Model, Estimation and Tests}

\subsection{The Model}

The population of interest consists of full-time employees of private firms and the public sector. Let $W_{1 i}$ be the hourly wage an individual $i$, randomly selected from this population, would earn as a public sector worker. Let $W_{2 i}$ be what the same individual would earn in the private sector. Denote by $U_{1 i}$ the maximum utility the individual would attain in the public sector, and by $U_{2 i}$ the corresponding utility in the private sector. Denote also $V_{1 i}=U_{1 i}-U_{2 i}$ . We say that $i$ prefers public sector employment to working for a private firm if and only if $V_{1 i}>0$. As is customary in the literature, I assume that 
$V_{1 i}$ is linear in the public sector's wage premium, $\ln W_{1 i}-\ln W_{2 i}$, and a set of observable characteristics, $Z_{1 i}$, of $i$. We can then write:

$$
V_{1 i}=\alpha_{1}\left(\ln W_{1 i}-\ln W_{2 i}\right)+Z_{1 i} \gamma_{1}+u_{1 i}
$$

where $\alpha_{1}$ is a constant, $\gamma_{1}$ is a vector of parameters including a constant term and $u_{1 i}$ is a random error term distributed normal with mean zero and variance $\sigma_{u_{1}}^{2}$.

Let $I_{1 i}$ be a dichotomous variable such that $I_{1 i}=1$ if $V_{1 i}>0$, and $I_{1 i}=0$, otherwise. The variable $V_{1 i}$ is not observable for any $i$. However, I assume that $I_{1 i}$ is unity for public sector workers. In contrast, we do not know the value of $I_{1 i}$ for any one in the private sector.

Equation 2.1 determines the queuing status of $i$ with respect to public sector employment. Following Abowd and Farber I will call it the 'in-queue' or IQ function of the model. It divides the population into two mutually exclusive groups $G_{1}$ and $G_{2}$ such that $i \in G_{1}$ if and only if $I_{1 i}=1$ and $i \in G_{2}$ if and only if $I_{1 i}=0$. Let the cost, to the public sector, of employing any $i \in G_{1}$ be $C_{1 i}$. I shall assume that $C_{1 i}=W_{1 i}+B_{1 i}$,where $B_{1 i}$ is hourly nonwage pecuniary benefits. I assume also that a public sector employer has no discretion in the determination of $C_{1 i}$. This is in the sense that, once $i \in G_{1}$ is in the public sector, $C_{1 i}$ is, on average, what government compensation rules prescribe it to be given the observable characteristics of $i$. However, it is entirely up to individual public sector employers to decide as to which workers in $G_{1}$ are to be recruited subject to the same compensation rules. I further assume that each public sector employer behaves as a cost minimiser in making this decision. Let $M_{1 i}$ be the hourly marginal value product of $i$ in the public sector. A cost minimising recruitment decision implies that $i$ is actually in the public sector if and only if $E\left(M_{1 i} \mid V_{1 i}>0\right)>E\left(C_{1 i} \mid V_{1 i}>0\right)$ . To simplify, let $\ln C_{1 i}$ be linear in $\ln W_{1 i}$. Assume also that $\ln M_{1 i}$ is linear in a set of observable characteristics $Z_{2 i}$ of $i$. Denoting $V_{2 i}=\ln M_{1 i}-\ln C_{1 i}$ ,we can write:

$$
\begin{aligned}
V_{2 i} & =\alpha_{2} E\left(\ln W_{1 i} \mid V_{1 i}>0\right)+Z_{2 i} \gamma_{2}+u_{2 i} \\
i & \in G_{1}
\end{aligned}
$$

where, $\alpha_{2}$ is a constant, $\gamma_{2}$ is a vector of parameters including a constant term and $u_{2 i}$ is a random error term distributed normal with zero mean and variance $\sigma_{u_{2}}^{2}$. 
Any individual $i \in G_{1}$ is chosen from the queue if and only if $V_{2 i}>0$ . Let $I_{2 i}$ be a second indicator variable such that $I_{2 i}=1$ if $V_{2 i}>0$, and $I_{2 i}=0$ otherwise. Equation 2.2 is what Abowd and Farber would call the 'chosen-from the queue' or CFQ function of the model. It further divides workers in $G_{1}$ into two distinct subgroups $G_{11}$ and $G_{12}$ such that $i \in G_{1}$ is in $G_{11}$ if and only if $I_{2 i}=1$ and $i \in G_{1}$ is in $G_{12}$ if and only if $I_{2 i}=0$. The IQ and CFQ functions together segment the entire population into three mutually exclusive groups, namely: (1) public sector workers, i.e., those in $G_{11}$; (2) private sector workers that are in the queue for public sector jobs, i.e., those in $G_{12}$; and (3) private sector workers who are not in the queue for public sector jobs, i.e., those in $G_{2}$. The sorting of the population between the private and public sectors can, of course, be described by a simple probit with a fully observable indicator variable $I_{i}$ such that $I_{i}=1$ if $i$ is in the public sector and $I_{i}=0$ if $i$ is in the private sector. However, it is clear that $I_{i}=I_{1 i} I_{2 i}$ if $i \in G_{1}$ and $I_{i}=I_{1 i}$, otherwise. This means that given that $i$ is observed in the public sector or that $I_{i}=1$, we can always infer that $I_{1 i}=1$ and $I_{2 i}=1$. The problem is that we cannot draw a similarly categorical conclusion from observing $I_{i}=0$. All that we can infer from observing that $i$ is actually in the private sector is that, either the worker is not in the queue for a public sector job (i.e., $I_{1 i}=0$ ), or is in the queue, but has failed to be selected by employers (i.e., $I_{1 i}=1$ and $I_{2 i}=0$ ). Equations 2.1 and 2.2 describe the sorting process as Poirier's probit by way of overcoming this ambiguity of the observation $I_{i}=0$. Because of the conditioning of equation 2.2 on the IQ function, the error term $u_{2 i}$ is distributed independently of $u_{1 i}{ }^{7}$

The ideal specification of the sorting process is a bivariate probit with full observablity, since this would lead to more efficient parameter estimates. Unfortunately it is impossible to observe the IQ and CFQ status of all workers at the same time from survey data. The use of Poirier's probit is a way of making up for this lack of information by exploiting the fact that a worker is observed in the public sector if and only if the worker wants to and, at

\footnotetext{
${ }^{7}$ This has the advantage of simplifying estimation without ruling out the possibility that the error term of the unconditional public sector 'job offer' function underlying the CFQ function is correlated with $u_{1 i}$. Its disadvantage (Maddala, 1983) is that we cannot make inferences about the unconditional job offer function itself unless we assume that the latter is independent of the IQ function. Note, though, that the assumption is not as restrictive as is sometimes suggested. This is because no economic meaning can be attached to the correlation between job offers and IQ status as long as queuing is costless.
} 
the same time, satisfies employers' selection criteria. The essence of the method is to match the characteristics of workers in the public sector with those of workers in the private sector, having distinguished first the set of characteristics that influence $\operatorname{Pr}\left(I_{i}=1\right)$ through their effect on the IQ status from the set of characteristics that influence the same probability through their effect on the CFQ status.

Equations 2.1 and 2.2 belong to a system I close by the following sectoral wage functions:

$$
\begin{aligned}
\ln W_{1 i} & =X_{i} \beta_{1}+v_{1 i} \\
\text { if } V_{1 i} & >0, V_{2 i}>0
\end{aligned}
$$

and

$$
\begin{aligned}
\ln W_{2 i}= & X_{i} \beta_{2}+v_{2 i}, \\
& \text { otherwise }
\end{aligned}
$$

where, $X_{i}$ is a vector of worker and industry characteristics, $\beta_{1}$ and $\beta_{2}$ are parameter vectors, $v_{1 i}$ is iid normal with mean zero and variance $\sigma_{v_{1}}^{2}$ and $v_{2 i}$ is distributed likewise but with variance $\sigma_{v_{2}}^{2}$. I will denote the covariance between $u_{1 i}$ and $v_{1 i}$ by $\sigma_{1 v_{1}}$, the covariance between $u_{1 i}$ and $v_{2 i}$ by $\sigma_{1 v_{2}}$, the covariance between $u_{2 i}$ and $v_{1 i}$ by $\sigma_{2 v_{1}}$ and the covariance between $u_{2 i}$ and $v_{2 i}$ by $\sigma_{2 v_{2}}$. Let $\omega^{\prime}=\left(u_{1 i}, u_{2 i}, v_{1 i}, v_{2 i}\right)$ and denote the covariance matrix, $E\left(\omega \omega^{\prime}\right)$, of the disturbance terms of the model by $\Sigma$. We have

$$
\Sigma=\left[\begin{array}{cccc}
\sigma_{u_{1}}^{2} & 0 & \sigma_{1 v_{1}} & \sigma_{1 v_{2}} \\
& \sigma_{u_{2}}^{2} & \sigma_{2 v_{1}} & \sigma_{2 v_{2}} \\
& & \sigma_{v_{1}}^{2} & \sigma_{12} \\
& & & \sigma_{v_{2}}^{2}
\end{array}\right]
$$

\subsection{Estimation}

Using equations 2.1 and 2.3 , we have

$$
E\left(\ln W_{1 i} \mid V_{1 i}>0\right)=X_{i} \beta_{1}+\sigma_{1 v_{1}} \lambda_{1 i}
$$

where $\lambda_{1 i}=\phi\left[E\left(V_{1 i} / \sigma_{u_{1}}\right)\right] / \Phi\left[E\left(V_{1 i} / \sigma_{u_{1}}\right)\right], \phi($.$) is the standard normal pdf$ and $\Phi($.$) is the standard normal cdf. Substituting equations 2.3$ and 2.4 into 2.1 , dividing through by $\sigma_{u_{1}}$ and rearranging gives

$$
I_{1 i}^{*}=X_{i} \alpha_{1}^{*}+Z_{1 i} \gamma_{1}^{*}+u_{1 i}^{*}
$$


where, $I_{1 i}^{*}=\left[V_{1 i}-\alpha_{1}\left(v_{1 i}-v_{2 i}\right)\right] / \sigma_{u_{1}}, \alpha_{1}^{*}=\left(\alpha_{1} / \sigma_{u_{1}}\right)\left(\beta_{1}-\beta_{2}\right), \gamma_{1}^{*}=\gamma_{1} / \sigma_{u_{1}}$ and $u_{1 i}^{*}=u_{1 i} / \sigma_{u 1}$. Substituting 2.5 into 2.2 , dividing through by $\sigma_{u_{2}}$ and rearranging gives

$$
I_{2 i}^{*}=X_{i} \alpha_{2}^{*}+Z_{2 i} \gamma_{2}^{*}+u_{2 i}^{*}
$$

where, $I_{2 i}^{*}=\left(V_{2 i}-\alpha_{2} \lambda_{1 i}\right) / \sigma_{u_{2}}, \alpha_{2}^{*}=\left(\alpha_{2} / \sigma_{u_{2}}\right) \beta_{1}, \gamma_{2}^{*}=\gamma_{1} / \sigma_{u_{2}}$ and $u_{2 i}^{*}=\frac{u_{2 i}}{\sigma_{u 2}}$. The sectoral wage equations can then be written as

$$
\begin{aligned}
& \ln W_{1 i}=X_{i} \beta_{1}+v_{1 i} \\
& \text { if } I_{1 i}^{*}>\alpha_{1} \frac{\left(v_{2 i}-v_{1 i}\right)}{\sigma_{u 1}} \text { and } I_{2 i}^{*}>-\alpha_{2} \frac{\lambda_{1 i}}{\sigma_{u 2}}
\end{aligned}
$$

and

$$
\begin{aligned}
\ln W_{2 i}= & X_{i} \beta_{2}+v_{2 i} \\
& \text { otherwise. }
\end{aligned}
$$

Equations 2.6 to 2.9 constitute the reduced form of the system of equations 2.1 to 2.4 . Let $c_{1}^{\prime}=\left(\alpha_{1}^{*^{\prime}}, \gamma_{1}^{*^{\prime}}\right), c_{2}^{\prime}=\left(\alpha_{2}^{*^{\prime}}, \gamma_{2}^{*^{\prime}}\right), \bar{Z}_{1 i}=\left[X_{i}, Z_{1 i}\right]$ and $\bar{Z}_{2 i}=$ $\left[X_{i}, Z_{2 i}\right]$. As shown in Poirier (1980) both $c_{1}$ and $c_{2}$ are identified as long as at least one variable in $\bar{Z}_{1 i}$ is excluded from $\bar{Z}_{2 i}$ or vice versa. It is clear from equations 2.6 and 2.7 that this condition is met if at least one variable in $Z_{1 i}$ is excluded from $Z_{2 i}$ or vice versa. Indeed, I shall assume that $Z_{2 i}$ is a proper subset of $Z_{1 i}$, that is, all individual characteristics that influence the IQ status also affect the CFQ status while the converse is not true. In particular, I shall assume that family background variables affect a worker's IQ status but have no influence on the probability of the worker being selected by public sector employers either directly or through their effect on the cost of employing the worker.

Given $c_{1}$, Lee (1979) has shown that both $\alpha_{1}^{*}$ and $\gamma_{1}^{*}$ are identified only if at least one variable exogenous variable in $X_{i}$ is excluded from $Z_{1 i}$. Similarly, a necessary condition for the identification of both $\alpha_{2}^{*}$ and $\gamma_{2}^{*}$ from $c_{2}$ is that at least one variable in $X_{i}$ is excluded from $Z_{2 i}$ : I shall use industry specific job attributes as means of identification in this context, by excluding them from both $Z_{1 i}$ and $Z_{2 i}$. The underlying assumption is that while the same attributes are important in wage determination in either sector, they have no direct influence either on the IQ probability or the CFQ probability. Given $\alpha_{1}^{*}$ and $\alpha_{2}^{*}$, the sample separation property of the model ensures that both $\beta_{1}$ and $\beta_{2}$ are identified. This guarantees that $\alpha_{1} / \sigma_{u_{1}}$ and $\alpha_{2} / \sigma_{u_{2}}$ are 
also identified. The parameters $\sigma_{v_{1}}^{2}, \sigma_{v_{2}}^{2}, \sigma_{1 v_{1}} / \sigma_{u_{1}}, \sigma_{1 v_{2}} / \sigma_{u_{1}}, \sigma_{2 v_{1}} / \sigma_{u_{2}}$, and $\sigma_{2 v_{2}} / \sigma_{u_{2}}$ are identified, again because of sample separation. However, sample separation also means that $\sigma_{12}$ cannot be identified from the reduced form of the model. We cannot identify either $\sigma_{u_{1}}^{2}$ and $\sigma_{u_{2}}^{2}$, which means that $\alpha_{1}$, $\alpha_{2}$ and the covariances between the error terms of the sorting equations and those of the wage functions can be identified only up to division by $\sigma_{u_{1}}$ or $\sigma_{u_{2}}$ as the case may be. I shall therefore use the normalisation $\sigma_{u_{1}}^{2}=\sigma_{u_{2}}^{2}=1$ through out the rest of the paper.

Let $\psi_{1 i}=\bar{Z}_{1 i} c_{1}$ and $\psi_{2 i}=\bar{Z}_{2 i} c_{2}$. Using the normalisation $\sigma_{u_{1}}^{2}=\sigma_{u_{2}}^{2}=1$ , the likelihood functions of the reduced form equations (2.6) to (2.9) is

$$
\begin{aligned}
L(\Theta)= & \prod_{i=1}^{N}\left[\int_{-\infty}^{-\psi_{2 i}-\psi_{1 i}} \int_{-\infty}^{\infty} H_{21}\left(u_{1 i} \mid v_{2 i}\right) H_{22}\left(u_{2 i} \mid v_{2 i}\right) g_{2}\left(v_{2 i}\right) d u_{1 i} d u_{2 i}\right]^{1-I_{i}} \\
& \left.\times\left[\int_{-\psi_{2 i}-\psi_{1 i}}^{\infty} \int_{11}^{\infty} H_{1 i} \mid v_{1 i}\right) H_{12}\left(u_{2 i} \mid v_{1 i}\right) g_{1}\left(v_{1 i}\right) d u_{1 i} d u_{2 i}\right]^{I_{i}}
\end{aligned}
$$

where, $\Theta^{\prime}=\left(\beta_{1}^{\prime}, \beta_{2}^{\prime}, \alpha_{1}, \alpha_{2}, \gamma_{1}^{\prime}, \gamma_{2}^{\prime}, \sigma_{v_{1}}^{2}, \sigma_{v_{2}}^{2}, \sigma_{1 v_{1}}, \sigma_{1 v_{2}}, \sigma_{2 v_{1}}, \sigma_{2 v_{2}}\right), N$ is sample size, $H_{j m}(), j,. m=1,2$ is the normal pdf of $u_{m i}$ conditional on $v_{j i}$, and $g_{j}($. is the marginal pdf of $v_{j i}$. Although maximisation of 2.10 would yield consistent and asymptotically efficient estimates of the parameters in $\Theta$, it is not attempted here. Instead I use that fact that the properties of the two stage structural probit analysis of Lee (1979) readily extend to the case of a model with two but independent switching rules. The first stage of the method consists in using probit maximum likelihood estimates $\widehat{c}_{1}$ and $\widehat{c}_{2}$ of the parameters $c_{1}$ and $c_{2}$ of the reduced form IQ and CFQ functions to obtain consistent estimates $\widehat{\Theta}_{1}$ of the parameters $\Theta_{1}^{\prime}=\left(\beta_{1}^{\prime}, \beta_{2}^{\prime}, \sigma_{v_{1}}^{2}, \sigma_{v_{2}}^{2}, \sigma_{1 v_{1}}, \sigma_{1 v_{2}}, \sigma_{2 v_{1}}, \sigma_{2 v_{2}}\right)$ through the Heckman-Lee modified least squares estimation of the sectoral wage equations. In the second stage, estimates of $\alpha_{1}, \alpha_{2}, \gamma_{1}$ and $\gamma_{2}$ are obtained by maximum likelihood from the probits

$$
V_{1 i}^{*}=X_{i}\left(\widehat{\beta}_{1}-\widehat{\beta}_{2}\right) \alpha_{1}+Z_{1 i} \gamma_{1}+\widetilde{u}_{1 i}
$$

and

$$
V_{2 i}^{*}=\left(X_{i} \widehat{\beta}_{1}+\widehat{\sigma}_{1 v_{1}} \hat{\lambda}_{1 i}\right) \alpha_{2}+Z_{2 i} \gamma_{2}+\widetilde{u}_{2 i}
$$

where, $\tilde{u}_{1 i}=u_{1 i}+X_{i}\left(\beta_{1}-\widehat{\beta}_{1}\right)+X_{i}\left(\beta_{2}-\widehat{\beta}_{2}\right)$ and $\widetilde{u}_{2 i}=u_{2 i}+X_{i}\left(\beta_{1}-\widehat{\beta}_{1}\right)+$ $\sigma_{1 v_{1}} \lambda_{1 i}-\widehat{\sigma}_{1 v_{1}} \hat{\lambda}_{1 i}$. Note that the disturbance term of each of these equations is 
asymptotically standard normal which follows from the standard normality of $u_{1 i}$ and $u_{2 i}$ and the consistency of $\widehat{\beta}_{1}, \widehat{\beta}_{2}$ and $\widehat{\sigma}_{1 v_{1}} \widehat{\lambda}_{1 i}$. The need for the second stage arises from the fact that, although $\alpha_{1}$ and $\alpha_{2}$ are both identified, a unique solution of either cannot be obtained form $\widehat{c}_{1}$ and $\widehat{c}_{2}$ since the model is overidentified. By a theorem due to Lee (1979, pp.986-88), the consistency of the two stage estimators $\hat{\alpha}_{1}, \hat{\alpha}_{2,}, \hat{\gamma}_{1}$ and $\widehat{\gamma}_{2}$ follows from the consistency of $\widehat{\beta}_{1}, \widehat{\beta}_{2}, \widehat{\sigma}_{1 v_{1}}$ and $\hat{\lambda}_{1 i}$ and the rank condition for the identification of $c_{1}$ and $c_{2}$ . Obtaining consistent estimates of $\beta_{1}, \beta_{2}$ and $\sigma_{1 v_{1}} \lambda_{1 i}$ is therefore the main task in the estimation of the model.

We have from equation 2.8 that

$$
E\left(v_{1 i} \mid I_{1 i}=1, I_{2 i}=1\right)=\sigma_{1 v_{1}} \lambda_{1 i}+\sigma_{2 v_{1}} \lambda_{2 i}
$$

where $\lambda_{1 i}=\phi\left(\bar{Z}_{1 i} c_{1}\right) / \Phi\left(\bar{Z}_{1 i} c_{1}\right)$ and $\lambda_{2 i}=\phi\left(\bar{Z}_{2 i} c_{2}\right) / \Phi\left(\bar{Z}_{2 i} c_{2}\right)$. Least squares estimation of equation 2.8 on any sample of public sector workers will not, therefore, yield a consistent estimate of $\beta_{1}$ unless $\sigma_{1 v_{1}}=\sigma_{2 v_{1}}=0$. If the error terms of the IQ and CFQ functions happen to be correlated with $v_{1 i}$, unbiased least squares estimation of $\beta_{1}$ requires the specification,

$$
\ln W_{1 i}=X_{i} \beta_{1}+\sigma_{1 v_{1}} \lambda_{1 i}+\sigma_{2 v_{1}} \lambda_{2 i}+\epsilon_{1 i}
$$

where,

$$
\epsilon_{1 i}=v_{1 i}-\sigma_{1 v_{1}} \lambda_{1 i}-\sigma_{2 v_{1}} \lambda_{2 i}
$$

so that $E\left(\epsilon_{1 i} \mid I_{i}=1\right)=0$. However, 2.14 cannot be estimated directly since $\lambda_{1 i}$ and $\lambda_{2 i}$ are unknown. The Heckman-Lee modified least squares procedure for consistent estimation of $\beta_{1}$ consists in the application of OLS to

$$
\ln W_{1 i}=X_{i} \beta_{1}+\sigma_{1 v_{1}} \hat{\lambda}_{1 i}+\sigma_{2 v_{1}} \hat{\lambda}_{2 i}+\eta_{1 i}
$$

where,

$$
\eta_{1 i}=\epsilon_{1 i}+\sigma_{1 v_{1}}\left(\lambda_{1 i}-\hat{\lambda}_{1 i}\right)+\sigma_{2 v_{1}}\left(\lambda_{2 i}-\hat{\lambda}_{2 i}\right),
$$

$\hat{\lambda}_{1 i}=\phi\left(\bar{Z}_{1 i} \widehat{c}_{1}\right) / \Phi\left(\bar{Z}_{1 i} \widehat{c}_{1}\right), \hat{\lambda}_{2 i}=\phi\left(\bar{Z}_{2 i} \widehat{c}_{2}\right) / \Phi\left(\bar{Z}_{2 i} \widehat{c}_{2}\right)$ and $\widehat{c}_{1}$ and $\widehat{c}_{2}$ are probit maximum likelihood estimates of $c_{1}$ and $c_{2}$ respectively.

The conditional wage equation of the private sector is not as readily identifiable since we do not observe the queuing status of this group of workers. For private sector workers that are not in the queue for public sector jobs, the conditional wage equation is

$$
\begin{aligned}
\ln W_{2 i}^{(1)} & =X_{i} \beta_{2}+\sigma_{1 v_{2}} \lambda_{3 i}+\epsilon_{2 i}^{(1)} \\
i & \in G_{2}
\end{aligned}
$$


where, $\lambda_{3 i}=-\phi\left(\bar{Z}_{1 i} c_{1}\right) /\left[1-\Phi\left(\bar{Z}_{1 i} c_{1}\right)\right]$ and $\epsilon_{2 i}^{(1)}=v_{2 i}-\sigma_{1 v_{2}} \lambda_{3 i}$. In contrast, the conditional wage equation for private sector workers that are in the queue for public sector jobs is

$$
\begin{aligned}
\ln W_{2 i}^{(2)} & =X_{i} \beta_{2}+\sigma_{1 v_{2}} \lambda_{1 i}+\sigma_{2 v_{2}} \lambda_{4 i}+\epsilon_{2 i}^{(2)} \\
i & \in G_{12}
\end{aligned}
$$

where, $\lambda_{4 i}=-\phi\left(\bar{Z}_{2 i} c_{2}\right) /\left[1-\Phi\left(\bar{Z}_{2 i} c_{2}\right)\right]$ and $\epsilon_{2 i}^{(2)}=v_{2 i}-\sigma_{1 v_{2}} \lambda_{1 i}+\sigma_{2 v_{2}} \lambda_{4 i}$ - However, consistent estimation of $\beta_{2}$ by the Heckman-Lee method does not require knowledge of the distribution of private sector workers between groups $G_{12}$ and $G_{2}$. Let the proportion of private sector workers who would rather be in the public sector be $\pi$. Then the expected wage of a worker randomly drawn from the sub population of private sector employees is given by $(1-\pi) E\left(\ln W_{2 i}^{(1)}\right)+\pi E\left(\ln W_{2 i}^{(2)}\right)$. This leads to the overall private sector conditional wage equation

$$
\begin{aligned}
\ln W_{2 i} & =X_{i} \beta_{2}+\sigma_{1 v_{2}} \lambda_{3 i}+\delta_{1} \lambda_{1 i}^{*}+\delta_{2} \lambda_{4 i}+\epsilon_{2 i} \\
i & \in\left[G_{2} \cup G_{12}\right]
\end{aligned}
$$

where, $\epsilon_{2 i}=(1-\pi) \epsilon_{2 i}^{(1)}+\pi \epsilon_{2 i}^{(2)}, \lambda_{1 i}^{*}=\lambda_{1 i}-\lambda_{3 i}, \delta_{1}=\pi \sigma_{1 v_{2}}$ and $\delta_{2}=\pi \sigma_{2 v_{2}}$. Consistent estimates of $\beta_{2}, \sigma_{1 v_{2}}, \delta_{1}$ and $\delta_{2}$ are obtained by applying least squares to

$$
\ln W_{2 i}=X_{i} \beta_{2}+\sigma_{1 v_{2}} \widehat{\lambda}_{3 i}+\delta_{1} \widehat{\lambda}_{1 i}^{*}+\delta_{2} \widehat{\lambda}_{4 i}+\eta_{2 i}
$$

where $\hat{\lambda}_{3 i}=-\phi\left(\bar{Z}_{1 i} \widehat{c}_{1}\right) /\left[1-\Phi\left(\bar{Z}_{1 i} \widehat{c}_{1}\right)\right], \hat{\lambda}_{1 i}^{*}=\widehat{\lambda}_{1 i}-\widehat{\lambda}_{3 i}$,

$$
\begin{aligned}
& \hat{\lambda}_{4 i}=-\phi\left(\bar{Z}_{2 i} \widehat{c}_{2}\right) /\left[1-\Phi\left(\bar{Z}_{2 i} \widehat{c}_{2}\right)\right] \text { and } \\
& \quad \eta_{2 i}=\epsilon_{2 i}+\sigma_{1 v_{2}}\left(\lambda_{3 i}-\hat{\lambda}_{3 i}\right)+\delta_{1}\left(\lambda_{1 i}^{*}-\hat{\lambda}_{1 i}^{*}\right)+\delta_{2}\left(\lambda_{4 i}-\hat{\lambda}_{4 i}\right)
\end{aligned}
$$

Although least squares applied to equations 2.16 and 2.21 gives consistent estimates of $\beta_{1}, \beta_{2}, \sigma_{1 v_{1}}, \sigma_{1 v_{2}}, \sigma_{2 v_{1}}, \sigma_{2 v_{2}}$ and $\pi$, it is clear form equations 2.17 and 2.22 , that the corresponding least squares estimates of the standard errors of the same parameter estimates are inconsistent as are least squares estimates of $\sigma_{v_{1}}^{2}$ and $\sigma_{v_{2}}^{2}$. Consistent estimates of $\sigma_{v_{1}}^{2}$ and $\sigma_{v_{2}}^{2}$ can, however, be obtained based on Tallis (1961) and Amemiya (1974). Let $\operatorname{var}\left(\epsilon_{1 i} \mid I_{i}=\right.$ 1) $=E\left(\epsilon_{1 i}^{2} \mid I_{i}=1\right)=\sigma_{\epsilon_{1 i}}^{2}$. Then equation 2.15 implies

$$
\sigma_{\epsilon_{1 i}}^{2}=\sigma_{v_{1}}^{2}-\sigma_{1 v_{1}}^{2} \lambda_{1 i}\left(\psi_{1 i}+\lambda_{1 i}\right)-\sigma_{2 v_{1}}^{2} \lambda_{2 i}\left(\psi_{2 i}+\lambda_{2 i}\right)
$$


Let $\widehat{\eta}_{1 i}$ be the $i^{\text {th }}$ residual of the least squares estimation of 2.16. By equation $2.17 \eta_{1 i}^{2}$ is the probability limit of $\epsilon_{1 i}^{2}$. A consistent estimator of $\sigma_{v_{1}}^{2}$ is, therefore,

$$
\widehat{\sigma}_{v_{1}}^{2}=\frac{1}{N_{1}} \sum_{i=1}^{N_{1}}\left(\widehat{\eta}_{1 i}^{2}+\widehat{d}_{1 i}\right)
$$

where $N_{1}$ is the size of the subsample of public sector workers,

$$
\widehat{d}_{1 i}=\widehat{\sigma}_{1 v_{1}}^{2} \widehat{\lambda}_{1 i}\left(\widehat{\psi}_{1 i}+\widehat{\lambda}_{1 i}\right)+\widehat{\sigma}_{2 v_{1}}^{2} \hat{\lambda}_{2 i}\left(\widehat{\psi}_{2 i}+\hat{\lambda}_{2 i}\right),
$$

$\widehat{\sigma}_{1 v_{1}}^{2}$ and $\hat{\sigma}_{2 v_{1}}^{2}$ are least squares estimates of $\sigma_{1 v_{1}}^{2}$ and $\sigma_{2 v_{1}}^{2}$ respectively, $\widehat{\psi}_{1 i}=$ $\bar{Z}_{1 i} \widehat{c}_{1}$ and $\widehat{\psi}_{2 i}=\bar{Z}_{2 i} \widehat{c}_{2}$. Similarly, let $\operatorname{Var}\left(\epsilon_{2 i} \mid I_{i}=0\right)=\sigma_{\epsilon_{2 i}}^{2}$. It can be shown that

$$
\begin{aligned}
\sigma_{\epsilon_{2 i}}^{2}= & \sigma_{v_{2}}^{2}-(1-\pi)^{2}\left[\sigma_{1 v_{2}}^{2} \lambda_{3 i}\left(\psi_{1 i}+\lambda_{3 i}\right)\right] \\
& -\pi^{2}\left[\sigma_{1 v_{2}}^{2} \lambda_{1 i}\left(\psi_{1 i}+\lambda_{1 i}\right)+\sigma_{2 v_{2}}^{2} \lambda_{4 i}\left(\psi_{2 i}+\lambda_{4 i}\right)\right] \\
& +2(1-\pi) \pi\left[\sigma_{1 v_{2}} \lambda_{3 i}\left(\sigma_{1 v_{2}} \lambda_{1 i}+\sigma_{2 v_{2}} \lambda_{4 i}\right)\right]
\end{aligned}
$$

A consistent estimator of $\sigma_{v_{2}}^{2}$ is

$$
\widehat{\sigma}_{v_{2}}^{2}=\frac{1}{N_{2}} \sum_{i=1}^{N_{2}}\left(\widehat{\eta}_{2 i}^{2}+\widehat{d}_{2 i}\right)
$$

where $N_{2}$ is the size of the sub-sample of private sector workers, $\widehat{\eta}_{2 i}$ is the $i^{\text {th }}$ least squares residual of equation 2.21 and

$$
\begin{aligned}
\widehat{d}_{2 i}= & (1-\widehat{\pi})^{2}\left[\widehat{\sigma}_{1 v_{2}}^{2} \hat{\lambda}_{3 i}\left(\widehat{\psi}_{1 i}+\widehat{\lambda}_{3 i}\right)\right] \\
& +\widehat{\pi}^{2}\left[\widehat{\sigma}_{1 v_{2}}^{2} \widehat{\lambda}_{1 i}\left(\widehat{\psi}_{1 i}+\widehat{\lambda}_{1 i}\right)+\widehat{\sigma}_{2 v_{2}}^{2} \widehat{\lambda}_{4 i}\left(\widehat{\psi}_{1 i}+\widehat{\lambda}_{4 i}\right)\right] \\
& -2(1-\widehat{\pi}) \hat{\pi}\left[\widehat{\sigma}_{1 v_{2}} \widehat{\lambda}_{3 i}\left(\widehat{\sigma}_{1 v_{2}} \widehat{\lambda}_{1 i}+\widehat{\sigma}_{2 v_{2}} \widehat{\lambda}_{4 i}\right)\right]
\end{aligned}
$$

The asymptotic standard errors of parameter estimates of 2.16 can be obtained using 2.24 based on Ham (1982). The latter extends the Lee et a.l (1980) correction to the case of a dual source of selectivity. Further extension to obtain the correct covariance matrix of the private sector wage equation, 2.21 is straightforward and is based on the first order approximation

$$
\eta_{2 i} \approx \epsilon_{2 i}+\sigma_{1 v_{1}} g_{3 i}^{\prime}(c-\widehat{c})+\delta_{1} \bar{g}_{1 i}^{\prime}(c-\widehat{c})+\delta_{2} g_{4 i}^{\prime}(c-\widehat{c})
$$


where, $g_{3 i}=\partial \lambda_{3 i} / \partial c, \bar{g}_{1 i}=\partial \lambda_{1 i}^{*} / \partial c$ and $g_{4 i}=\partial \lambda_{4 i} / \partial c$ are gradient vectors, $c^{\prime}=\left[c_{1}, c_{2}\right]$ and $\widehat{c}^{\prime}=\left[\widehat{c}_{1}, \widehat{c}_{2}\right]$. Let $\widetilde{X}_{2 i}=\left(X_{i}, \widehat{\lambda}_{3 i}, \hat{\lambda}_{1 i}^{*}, \hat{\lambda}_{4 i}\right), \widetilde{\beta}_{2}^{\prime}=$ $\left[\beta_{2}^{\prime}, \sigma_{1 v_{2}}, \delta_{1}, \delta_{2}\right], \widetilde{X}_{2}=\left(\widetilde{X}_{21}, \widetilde{X}_{22}, \ldots, \widetilde{X}_{2 N_{2}}\right), \eta_{2}^{\prime}=\left(\eta_{21}, \eta_{22}, \ldots, \eta_{2 N_{2}}\right), \epsilon_{2}^{\prime}=$ $\left(\epsilon_{21}, \epsilon_{22}, \ldots, \epsilon_{2 N_{2}}\right), \bar{G}_{2 i}=\sigma_{1 v_{2}} g_{3 i}+\delta_{1} \bar{g}_{1 i}+\delta_{2} g_{4 i}$ and $\bar{G}_{2}^{\prime}=\left(\bar{G}_{21}, \bar{G}_{22}, \ldots, \bar{G}_{2 N_{2}}\right)$

. Then

$$
\begin{aligned}
\widetilde{\tilde{\beta}}_{2}-\widetilde{\beta}_{2}= & \left(\widetilde{X}_{2}^{\prime} \widetilde{X}_{2}\right)^{-1} \widetilde{X}_{2}^{\prime} \eta_{2} \\
& \underline{\underline{A}}\left(\widetilde{X}_{2}^{\prime} \widetilde{X}_{2}\right)^{-1} \widetilde{X}_{2}^{\prime}\left[\epsilon_{2}+\bar{G}_{2}(c-\widehat{c})\right]
\end{aligned}
$$

where, $\widehat{\widetilde{\beta}}_{2}^{\prime}=\left(\widehat{\beta}_{2}^{\prime}, \widehat{\sigma}_{1 v_{1}}, \widehat{\delta}_{1}, \widehat{\delta}_{2}\right)$ is the least squares estimate of $\tilde{\beta}_{2}$.It can be shown that $E\left[(c-\widehat{c}) \epsilon_{2}\right]=0$ so that

$$
\operatorname{var}\left(\widetilde{\tilde{\beta}}_{2}\right)=\left(\widetilde{X}_{2}^{\prime} \widetilde{X}_{2}\right)^{-1}\left[\widetilde{X}_{2}^{\prime} \Omega \widetilde{X}_{2}\right]\left(\widetilde{X}_{2}^{\prime} \widetilde{X}_{2}\right)^{-1}
$$

where $\Omega=\operatorname{var}\left(\epsilon_{2}\right)+\bar{G}_{2} \operatorname{var}(\hat{c}) \vec{G}_{2}^{\prime}$ and $\operatorname{var}\left(\epsilon_{2}\right)=\operatorname{Diag}\left(\sigma_{\epsilon_{2 i}}^{2}\right)$. Let $\hat{\bar{G}}_{2}$ be our estimate of $\bar{G}_{2}$ obtained by replacing $\lambda_{3 i}, \lambda_{1 i}^{*}$ and $\lambda_{4 i}$ by $\hat{\lambda}_{3 i}, \widehat{\lambda}_{1 i}^{*}$ and $\hat{\lambda}_{4 i}$ respectively. Then the variance of $\widehat{\widetilde{\beta}}_{2}$ is consistently estimated by

$$
\widehat{\operatorname{var}}\left(\widetilde{\tilde{\beta}}_{2}\right)=\left(\widetilde{X}_{2}^{\prime} \widetilde{X}_{2}\right)^{-1}\left[\widetilde{X}_{2}^{\prime} \widehat{\Omega} \widetilde{X}_{2}\right]\left(\widetilde{X}_{2}^{\prime} \widetilde{X}_{2}\right)^{-1}
$$

where $\widehat{\Omega}=\operatorname{Diag}\left(\widehat{\eta}_{2 i}^{2}\right)+\hat{\bar{G}}_{2} \widehat{\operatorname{var}}(\widehat{c}) \hat{\bar{G}}_{2}^{\prime}$.

\subsection{Testing For A Job Queue}

The parameter $\pi$ in equation 2.21 is the proportion of private sector workers who have been rationed out of the public sector and can be estimated consistently since it is identified in the same equation. ${ }^{8}$ The existence or otherwise of a public sector job queue can be tested on the basis of the first stage estimation of the reduced form IQ and CFQ probits, which is the procedure used by Abowd and Farber(1982). In the absence of a queue the reduced form of the switch between private and public sector jobs is given by equation 2.6, which is obtained by the restriction that all the elements of $c_{2}$ are

\footnotetext{
${ }^{8}$ I estimate $\pi$ by $\widehat{\pi}=\widehat{\delta}_{1} / \widehat{\sigma}_{1 v_{2}}$ the consistency of which follows from that of $\widehat{\delta}_{1}$ and $\widehat{\sigma}_{1 v_{2}}$ by Slutsky's Theorem.
} 
zero with the exception of the constant term which now assumes an arbitrary positive number large enough to ensure that $\operatorname{pr}\left(I_{2 i}=1 \mid I_{1 i}=1\right)=1$ for all $i$. The opposite of this 'no queue' scenario is the case of a 'universal job queue' where, the reduced form the sorting mechanism is described by equation 2.7 . A universal queue is equivalent to the restriction on 2.6 and 2.7 that all the elements of $c_{1}$ are zero except for the constant term which is now an arbitrary positive number large enough to ensure that $\operatorname{pr}\left(I_{1 i}=1\right)=1$ for all $i$. I will refer to the likelihood ratio test of either restriction as Abowd and Farber's test for a job queue to distinguish it from an alternative test based on the estimates of the conditional private sector wage equation. The latter is based on the fact that the no-queue model implies that $\pi=0$ while a universal job queue model means $\pi=1$. A rejection of both the no-queue and the universal queue restrictions implies a regime of a partial job queue, in which some but not all private sector workers are in the queue for a public sector job, that is, one in which $0<\pi<1$. I will refer to the unrestricted model,where $0 \leq \pi \leq 1$, as 'the queue' model. The asymptotic joint significance test of $\delta_{1}$ and $\delta_{2}$ is a test of the null $\pi=0$. Similarly, the asymptotic F-test of the restriction $\sigma_{1 v_{2}}=\delta_{1}$ is a test of the null $\pi=1^{9}$. It should be noted that the conditional wage equation 2.21 can be interpreted as a compound model nesting the no-queue and universal queue specifications of equations 2.18 and 2.19 , with $\pi$ as the analogue to the nesting parameter of the $J$-test (Davidson and Mackinnon, 1982). The difference between the standard J-test setting and the present case is that the, $\pi$ here is not an artificial nesting device but a parameter of economic meaning. Because all its parameters are identified, the general model in our case is also directly estimable, without the need to first estimate either special case. With this caveat in mind I will refer to tests of the no-queue and the universal queue models based on equation 2.21 as the J-test for a job queue. Since there is no guarantee that the two tests yield the same result in any particular sample, outcomes of both tests will be reported in the next section.

\footnotetext{
${ }^{9}$ As shown by Ahn (1992), the approximate F-statistic of a model with a dual selection mechanism is asymptotically equivalent to the LM test statistic.
} 


\section{Empirical Results}

\subsection{Data and Variables}

The data analysed consist of observations on 1170 individuals who worked as full-time wage employees of private firms and public sector organisations in Ethiopia's major towns in 1994. These were drawn from the 1994 wave of the SSUH survey as a subsample obtained by eliminating individuals who were out of the labour force, unemployed, self-employed or worked as casual or part-time workers or as domestic workers at the time of the survey. ${ }^{10}$ Just over 63 per cent of those in the sample were public sector employees at the time of the survey, which is similar to figures reported for many other African countries.

The dependent variable of the estimated wage equations is the natural logarithm of hourly wages in Birr. ${ }^{11}$ The set of variables, $X_{i}$, included in the public sector wage equation are the same as those include in the private sector equation although this is not a requirement of the model. Descriptive statistics of the relevant variables are given in Table 3.1. Standard earnings function regressors are denoted as follows :

EDUC = number of years of schooling;

EXPR $=$ age minus 6 minus years of schooling, measuring potential market experience;

EXPRSQ $=$ the square of EXPR;

TENURE = number of years in the current job;

TENURESQ $=$ square of TENUER.

The remaining variables in $X_{i}$ are all dichotomous and are defined as follows:

GENDER $=1$ if the worker is male ;

NONADDIS $=1$ if the worker resides in a regional urban centre, i.e., in a town other than the capital;

\footnotetext{
${ }^{10}$ The main reason for the exclusion of domestic workers from the sample was that inkind payments in the form of food and lodging are typically a very large proportion of wages for the group in Ethiopia at the moment. This means that a dummy variable would have to be included for the group in the estimation of the private sector wage equation to avoid the measurment error that would otherwise arise.Unfortunately the same variable cannot appear in the reduced form sorting probits since it would be collinear to the indicator variables which makes estimation impossible.

${ }^{11}$ The Birr is Ethiopia's currency. It's official exchange rate to the US dollar stood at Birr 6.5 at the time of the survey.
} 
Table 1: Descriptive Statistics.

\begin{tabular}{l|l|l|l|l|ll}
\hline \multirow{2}{*}{ Variable } & \multicolumn{2}{l|}{ Public Sector } & \multicolumn{2}{l|}{ Private Sector } & \multicolumn{2}{l}{ All Workers } \\
\cline { 2 - 7 } & Mean & $\begin{array}{l}\text { Standard } \\
\text { deviation }\end{array}$ & Mean & $\begin{array}{l}\text { Standard } \\
\text { deviation }\end{array}$ & Mean & $\begin{array}{l}\text { Standard } \\
\text { deviation }\end{array}$ \\
\hline LNWAGE & 0.62 & 0.74 & 0.12 & 0.99 & 0.44 & 0.88 \\
EDUC & 10.26 & 4.18 & 7.33 & 4.72 & 9.18 & 4.61 \\
EDUCSQ & 122.75 & 74.36 & 75.96 & 73.04 & 105.51 & 77.22 \\
EXPR & 20.22 & 11.46 & 19.05 & 14.73 & 19.79 & 12.76 \\
EXPRSQ & 539.91 & 569.98 & 579.18 & 805.83 & 554.38 & 666.57 \\
TENURE & 11.83 & 8.82 & 6.46 & 8.33 & 9.85 & 9.02 \\
TENURESQ & 217.54 & 270.22 & 110.91 & 249.54 & 178.26 & 267.68 \\
GENDER & 0.61 & 0.49 & 0.74 & 0.44 & 0.66 & 0.48 \\
NONADDIS & 0.40 & 0.49 & 0.24 & 0.43 & 0.34 & 0.47 \\
PROFTECH & 0.28 & 0.45 & 0.13 & 0.33 & 0.22 & 0.42 \\
ADMCLER & 0.23 & 0.42 & 0.16 & 0.37 & 0.21 & 0.40 \\
FATOWNAC & 0.15 & 0.35 & 0.13 & 0.34 & 0.14 & 0.35 \\
FATPRWAG & 0.03 & 0.18 & 0.12 & 0.32 & 0.06 & 0.25 \\
FATPUWAG & 0.21 & 0.41 & 0.15 & 0.36 & 0.19 & 0.39 \\
FOODBEV & 0.04 & 0.21 & 0.04 & 0.19 & 0.04 & 0.20 \\
OTHINDUS & 0.06 & 0.25 & 0.19 & 0.39 & 0.11 & 0.31 \\
OTHMANU & 0.16 & 0.36 & 0.19 & 0.39 & 0.17 & 0.38 \\
\hline Number of obs. & 739 & \multicolumn{3}{|l|}{431} & \multicolumn{3}{l|}{1170} & \\
\hline
\end{tabular}

PROFTECH $=1$ if the worker's main occupation is professional or technical;

ADMCLER $=1$ if the worker has not been trained as a professional or technical worker but mainly does an administrative or clerical work;

FOODBEV $=1$ if the worker is employed in the food or beverages industries;

OTHMANU $=1$ if the worker is employed in a manufacturing industry other than the food and beverages industries;

OTHINDUS $=1$ if the worker is employed in a non-service, non-manufacturing industry.

Although the market experience of the average public sector worker is comparable to that of the average private sector employee, public sector workers have twice as many years of tenure over the current job at 12 years as private sector workers. The average public sector worker is also better ed- 
ucated than the average private sector employee. The mean level of schooling for the full sample is 9 years, which compares to a figure of 10.3 years in the public sector and 7.3 years in the private sector. The proportion of women in the work force is also much higher in the public sector at just under forty per cent against a figure of 26 per cent in the private sector. Turning to the breakdown of work force by occupational groups, we see that more than half of public sector workers do professional/technical or administrative or clerical jobs against a 28 per cent share of the same groups in the private sector. Two thirds of public sector workers also work in service industries which is twice the figure in the private sector. The proportion of workers engaged in the food or beverages industries is similar for the two sectors. However, a much higher proportion of the work force is engaged in the manufacturing and other non-service industries in the private sector than is the case in the public sector. I finally note that only 40 per cent of public sector workers in the sample reside in regional urban centres as opposed to the capital city. The proportion is even lower at 24 per cent for private sector worker. The public sector figure is broadly consistent with the division of the urban population in Ethiopia between regional urban centres and the capital.

Of all of the variables in $X_{i}$, only the industry dummies, FOODBEV, OTHMANU and OTHINDUS are excluded from the $Z_{1 i}$ and $Z_{2 i}$ of the structural probits. The inclusion of the remaining variables in the exogenous variables, $Z_{1 i}$, of the IQ functions is based on the possibility that age, gender, tenure, occupation and residence may all be expressions of variation in attitudes to risk or taste vis-a-vis other job attributes and, consequently, are not necessarily fully captured by contemporaneous wage differentials. The inclusion of the same variables in the exogenous variables, $Z_{2 i}$, of the CFQ function can be justified in similar terms: for a given wage structure, employers may prefer a particular age, gender, education or experience group to others either because non-wage costs of employment or productivity or both happen to vary with the same variables while the location and nature of public sector activities may result in the predominance of certain occupations or locations in the distribution of public sector jobs. It is possible that the effect of schooling on worker sectoral preferences or non-wage employment costs or productivity is non-linear. I therefore include the variable EDUCSQ, which is defined as the square of EDUC, in both $Z_{1 i}$ and $Z_{2 i}$

Apart form EDUCSQ, $Z_{1 i}$ includes three other variables that are excluded from both $X_{i}$ and $Z_{2 i}$. These are all dichotomous indicators of paternal occupation and are defined as follows: 
FATPUWAG $=1$ if the worker's father works or worked mainly as a public sector employee;

FATPRWAG $=1$ if the worker's father works or worked mainly as an employee of a private firm; and

FATOWNAC $=1$ if the worker's father works or worked mainly as a nonfarm own-account worker.

The base group for the definition of these variables are workers whose fathers mainly work or worked as traditional farmers. More than 60 per cent of workers in the sample belong to this group, or are first generation urban dwellers, which is a reflection of the very recent nature of urbanisation in Ethiopia. Approximately a fifth of the sample have or had fathers who worked in the urban private sector as wage employees or own-account workers. Fathers of a similar proportion of the sample were public sector workers. The hypothesis is that family background as indicated by paternal occupation influences the attitude of workers to particular attributes of jobs on offer. ${ }^{12}$ A possible justification for this is that parents values and attitudes may somehow be passed down to children in their upbringing. On the other hand the highly centralised nature of vacancy advertisement and the screening of job applicants in Ethiopia's public sector suggests that the same variables are unlikely to have a significant influence on wage determination or the probability of an individual being selected from a possible job queue. ${ }^{13}$ Hence the exclusion of paternal occupation variables from $Z_{2 i}$ as well as from $X_{i}$.

\subsection{Estimates of Reduced Form IQ and CFQ Probits}

I report in Table 3.2 maximum likelihood estimates of the parameters of the reduced form selection rules of the queue model. Corresponding estimates of the selection rule of the no-queue model are given in columns 1 and 2 of Table 3.3, while those of the selection rule of the universal-queue model are reported in columns 3 and 4 of the same table. The log likelihood ratio of Abowd and Farber's test of the no-queue model is 73.8 at 14 degrees of freedom which compares to a critical value of 33.4 at the one per cent level

\footnotetext{
${ }^{12}$ The use of maternal occupation as an indicator of family background is not possible because of lack of variation in the empolment status of mothers. An extremly high proportion reported that their mothers were mainly housewives.

${ }^{13} \mathrm{~A}$ more detailed comparison of the job-matching process in the public sector with that of the private sector is given in Chapter 7 in relation to manufacturing industries.
} 
Table 2: Maximum Likelihood Estimates of the Sorting Probits of the Reduced Form Job Queue Model.

\begin{tabular}{|c|c|c|c|c|c|}
\hline \multirow[t]{2}{*}{ Variable } & \multicolumn{2}{|c|}{ IQ Function } & & \multicolumn{2}{|c|}{ CFQ Function } \\
\hline & Coefficient & $\begin{array}{l}\text { Standard } \\
\text { error }\end{array}$ & & Coefficient & $\begin{array}{l}\text { Standard } \\
\text { error }\end{array}$ \\
\hline Constant & 1.5442 & 0.6155 & & -1.609 & 0.2628 \\
\hline EDUC & 0.1483 & 0.0654 & & -0.0116 & 0.0821 \\
\hline EDUCSQ & -0.0099 & 0.0035 & & 0.0135 & 0.0058 \\
\hline EXPR & -0.0379 & 0.0254 & & 0.01654 & 0.0034 \\
\hline EXPRSQ & -0.0003 & 0.0004 & & 0.0013 & 0.0011 \\
\hline TENURE & 0.0673 & 0.0303 & & 0.1619 & 0.0365 \\
\hline TENURESQ & -0.001 & 0.0009 & & -0.0036 & 0.0016 \\
\hline GENDER & -0.2264 & 0.1842 & & -0.6978 & 0.1588 \\
\hline FATPRWAG & -1.2762 & 0.2816 & & & \\
\hline FATPUWAG & 0.2499 & 0.2433 & & & \\
\hline FATOWNAC & -0.25 & 0.2311 & & & \\
\hline ADMCLER & -0.2254 & 0.2634 & & -0.002 & 0.2159 \\
\hline PROFTECH & -0.0963 & 0.2309 & & 0.5107 & 0.2535 \\
\hline FOODBEV & -0.4603 & 0.3742 & & 0.4126 & 0.5247 \\
\hline OTHMANU & -0.2576 & 0.2462 & & -0.5588 & 0.201 \\
\hline OTHINDUS & -0.833 & 0.2321 & & -0.1796 & 0.2819 \\
\hline NONADDIS & 0.8418 & 0.1932 & & 0.34 & 0.1648 \\
\hline Log likelihood & & & -522.67 & & \\
\hline Number of observations & & & 1170 & & \\
\hline
\end{tabular}

of significance. The universal-queue model is as easily rejected by the same test with a likelihood ratio of 96 at 17 degrees of freedom.

It should be noted that the estimates reported in columns 1 and 2 of Table 3.3 are always correct as a description of the determination of the probability of a worker having a public sector job regardless of whether or not the noqueue model accurately describes the sorting mechanism between private and public sector jobs. The validity or otherwise of the no-queue model matters only in the interpretation of the same probability. If the no-queue model is accepted as the correct description of the allocation of workers between the two sectors, then the probability of having a public sector job is the same as the probability of wanting the same job. The latter is not, of course, correct if the no-queue model is rejected in favour of the queue model. Since this is, 
Table 3: Maximum Likelihood Estimates of Sorting Probits of the Reduced Form No-queue and Universal Queue Models.

\begin{tabular}{lll|ll}
\hline Variable & \multicolumn{2}{l|}{ No-queue Model } & Universal Queue Model \\
\cline { 2 - 5 } & Coefficient & $\begin{array}{l}\text { Standard } \\
\text { error }\end{array}$ & Coefficient & $\begin{array}{l}\text { Standard } \\
\text { error }\end{array}$ \\
\hline Constant & -1.3981 & 0.1948 & -1.5 & 0.1898 \\
EDUC & 0.1694 & 0.0383 & 0.1622 & 0.0376 \\
EDUCSQ & -0.0041 & 0.0023 & -0.0038 & 0.0022 \\
EXPR & 0.0217 & 0.0118 & 0.0259 & 0.0117 \\
EXPRSQ & -0.0004 & 0.0002 & -0.0004 & 0.0002 \\
TENURE & 0.1325 & 0.0158 & 0.1326 & 0.0158 \\
TENURESQ & -0.0030 & 0.0005 & -0.0029 & 0.0005 \\
GENDER & -0.5449 & 0.0969 & -0.5245 & 0.0950 \\
FATPRWAG & -0.7860 & 0.1843 & & \\
FATPUWAG & -0.0734 & 0.1223 & & \\
FATOWNAC & -0.1740 & 0.1323 & & \\
ADMCLER & -0.0691 & 0.1227 & -0.0751 & 0.1218 \\
PROFTECH & 0.2331 & 0.1278 & 0.2162 & 0.1266 \\
FOODBEV & 0.0385 & 0.2122 & 0.0330 & 0.2078 \\
OTHMANU & -0.3011 & 0.1171 & -0.3289 & 0.1160 \\
OTHINDUS & -0.5185 & 0.1393 & -0.5108 & 0.1375 \\
NONADDIS & 0.6395 & 0.1393 & 0.6535 & 0.0980 \\
Log-likelihood & -559.56 & & -570.72 & \\
Number of observations & 1170 & & 1170 & \\
\hline & & & & \\
\hline
\end{tabular}


in fact, the case, we should read columns 1 and 2 of the table as nothing more than a description of the determination of the probability of a worker being found in the public sector. Table 3.2 then tells us as to how the influence of a given variable on the same probability divides into a component transmitted through the IQ probability and one transmitted through the CFQ probability. It is thus possible that a variable which has a strong influence on one of the IQ or CFQ probabilities appears not to affect at all the probability of a worker actually being found in the public sector simply because its effect countervails the effect on the other probability. On the other hand, a variable that shows up as a strong influence on the probability of public sector employment may bear no relationship to one of the IQ probability or to the CFQ probability.

Thus we see from Table 3.2 that women are more likely to have a public sector job than men not because they are more likely to prefer public sector employment, but because, among those that do have such preference, they are more likely to be selected by public sector employers. Similarly, professional or technical workers are more likely to be found in the public sector than other occupational groups, not because they are more likely to choose the same sector, but because they are more likely to be chosen from the public sector job queue. On the other hand, a wage-employee in a regional urban centre is more likely to be found in the public sector than a similar worker in Addis Ababa both because regional workers are more likely to prefer public sector employment and because the same group of workers are more likely to be selected by the public sector. Likewise, industrial workers are less likely to be public sector employees than service workers, both because they are less likely to choose public sector jobs and because public sector demand for such workers is lower. A similar decomposition cannot be made of the influence of family background on the probability of a worker's public sector employment, since the corresponding variables are excluded from the CFQ function as a means of identifying the parameters of both functions. In as far as this exclusion is valid, I interpret the results reported in the table as indicative of a significant influence of family background on choice of sector. This is in the sense that workers whose father's are or were in private sector wage or non-farm self-employment are less likely to prefer public sector jobs than workers whose paternal occupation was traditional farming.

Turning to the effect of conventional human capital variables, we should note that the variable TENURE, in the present context is an indicator of job security from the point of view of workers and firm-specific experience from the point of view of employers. Because the mean public sector job tenure 
Table 4: Probabilities of IQ and CFQ Status as Functions of Schooling, Reduced Form Job Queue Model

\begin{tabular}{l|ll|ll|ll} 
& \multicolumn{3}{|l}{ (Standard errors in parentheses.) } \\
\hline $\begin{array}{l}\text { Years of } \\
\text { Schooling }\end{array}$ & IQ status & \multicolumn{3}{l|}{ CFQ status } & \multicolumn{2}{l}{ Public sector employment } \\
\cline { 2 - 7 } & Probability & $\begin{array}{l}\text { Marginal } \\
\text { effect }\end{array}$ & Probability & $\begin{array}{l}\text { Marginal } \\
\text { effect }\end{array}$ & Probability & $\begin{array}{l}\text { Marginal } \\
\text { effect }\end{array}$ \\
\hline 1 & 0.9062 & 0.0249 & 0.0105 & -0.0003 & 0.026 & 0.0102 \\
6 & $(0.1142)$ & $(0.0285)$ & $(0.0083)$ & 0.0024 & $(0.0124)$ & $(0.0033)$ \\
8 & 0.9679 & 0.0021 & 0.0293 & 0.01 & 0.1411 & 0.0268 \\
12 & $(0.0432)$ & $(0.0039)$ & $(0.0195)$ & 0.0060 & $(0.0354)$ & $(0.0056)$ \\
& 0.9692 & -0.0007 & 0.0622 & 0.0250 & 0.1970 & 0.0287 \\
16 & $(0.0391)$ & $(0.0018)$ & $(0.0353)$ & 0.0287 & $(0.0434)$ & $(0.0066)$ \\
& 0.9692 & -0.0062 & 0.3068 & 0.1096 & 0.1970 & 0.0195 \\
& $(0.3049)$ & $(0.0053)$ & $(0.0891)$ & 0.0274 & $(0.0415)$ & $(0.0066)$ \\
& 0.8757 & -0.0346 & 0.8311 & 0.1058 & 0.3856 & 0.0142 \\
& $(0.0945)$ & $(0.0224)$ & $(0.1093)$ & 0.0277 & $(0.0719)$ & $(0.0561)$ \\
\hline
\end{tabular}

* Base group characteristics: a male worker residing in the capital with no market experience, no current job tenure, a traditional farmer as a father and employed in a non-professional, non-technical job in the services industry

is twice the figure for the private sector, workers attaching greater weight to job security are more likely to prefer the public sector, while the public sector would prefer workers with more in-house experience. I therefore expect both the IQ and CFQ probabilities to increase with tenure over the current job, which is what we see in Table 3.2. However, we also see that the impact of the same variable on the probability of having a public sector job occurs more through the CFQ probability than through the IQ probability.

The effects of education and market experience on the IQ and CFQ functions is analysed in Tables 3.4 and 3.5. The base group used for computing results of Table 3.4 consists of male workers residing in Addis with negligible market experience, negligible tenure over the current job, a traditional farmer as a father and employed in a non-professional, non-technical, nonadministrative job in a service industry. The base group used for the computation of Tables 3.5 consists of workers with 9 years of schooling and a variable market experience but otherwise having the same characteristics as the base group of Tables 2.4. Following Abowd and Farber, it can be argued that if public sector wage rates are more standardised or compressed than 
Table 5: Probabilities of IQ and CFQ Status as Functions of Market Experience, Reduced Form Job Queue Model.

\begin{tabular}{l|ll|ll|l} 
& \multicolumn{5}{l|}{ (Standard errors in parentheses) } \\
\hline \multirow{2}{*}{$\begin{array}{l}\text { Experience } \\
\text { (years) }\end{array}$} & IQ status & & CFQ status & \\
\cline { 2 - 5 } & Probability & $\begin{array}{l}\text { Marginal } \\
\text { effect }\end{array}$ & Probability & $\begin{array}{l}\text { Marginal } \\
\text { effect }\end{array}$ & \\
\hline 0 & 0.9678 & -0.0027 & 0.0935 & 0.0028 & 0.2257 \\
5 & $(0.0396)$ & $(0.0022)$ & $(0.0466)$ & $(0.0049)$ & $(0.0465)$ \\
5 & 0.9507 & -0.0042 & 0.1145 & 0.0058 & 0.2566 \\
10 & $(0.0494)$ & $(0.0030)$ & $(0.0372)$ & $(0.0042)$ & $(0.0409)$ \\
15 & 0.9246 & -0.0063 & 0.1538 & 0.0103 & 0.2832 \\
& $(0.0625)$ & $(0.0039)$ & $(0.0416)$ & $(0.0042)$ & $(0.0397)$ \\
20 & 0.9246 & -0.0068 & 0.1538 & 0.0134 & 0.3045 \\
& $(0.0582)$ & $(0.0038)$ & $(0.0446)$ & $(0.0046)$ & $(0.0470)$ \\
& 0.8469 & -0.0122 & 0.2355 & 0.0216 & 0.3198 \\
& $(0.1006)$ & $(0.0057)$ & $(0.0946)$ & $(0.0066)$ & $(0.0448)$ \\
\hline
\end{tabular}

Note: Base group characteristics: a male worker residing in the capital with 9 years of schooling, no current job tenure, a traditional farmer as a father and employed in a non-professional, non-technical job in the services industry 
private sector rates, either because of the greater degree of unionisation of public sector jobs or as a matter of a centralised public sector pay policy, then a person's desire for a public sector job should diminish with the person's skill as measured by schooling or the level of market experience. On the other hand, since the same compression of rates amounts to a lowering of the relative price of higher grades of skill, its effect on a cost minimising public sector employer is to make the employer recruit more skilled workers than the private sector as long as technology is one of substantial elasticity of substitution between skill grades. In other words, we expect the CFQ function to increase in schooling and experience while the IQ function decreases in both. This, indeed, is what the data suggest. For instance, we see from columns 1 and 3 of Table 3.4 that practically everyone with 8 years of schooling or less in the base group is in the queue for public sector jobs, while the probability of being selected from the queue is substantial only for those with 8 years or more of schooling. The result comes out even more forcefully in the second and fourth colums of the same table, where the marginal effect of schooling on the IQ probability is almost zero for those with less than 12 years of schooling and negative for those with 12 years or more education. In contrast, the marginal effect of schooling on the CFQ probability is positive and significant for those with 6 years of schooling or more. The picture is more or less the same when it comes to the influence of market experience. Here also, practically every one with 15 years of experience or less is in the queue, while the probability of being chosen from the queue is substantial only for those with more than 15 years of experience as can be seen from the first and third columns of Table 3.5. This translates to the result, in the second and fourth columns, that the marginal effect of market experience on the IQ probability is practically zero for those with below 15 years of experience while the marginal effect of the same variable on the CFQ probability is positive, significant, and increasing for those with 10 years or more of experience.

\subsection{Estimated Wage Equations}

The least squares estimates of the sectoral wage equations are reported in Table 3.6. As can be seen from the table the goodness of fit of the public sector equation is quite high by the standards of estimates reported for both developed and developing economies. The fit of the private sector equation is not as good, but is also comparable to those reported in, for example, Lin- 
dauer and Sabot (1983), Terrel (1993) and Hartog and Oosterbeek (1993). In both cases, the coefficients of the human capital variables are highly significant, have the expected signs and imply a strictly concave experience-earning and tenure-earning profiles. The coefficients of education are comparable in magnitude to those reported by Gyourko and Tracy (1988) and Bjorklund and Moffit (1987). The magnitudes of the coefficients of the market experience variables are similar to those reported in Robinson and Tommes (1984), Lindauer and Sabot (1983), Gyourko and Tracy (1988), Hartog and Oosterbeek (1993) and Terrel (1993). We also see that the rate of return to schooling is higher in the public sector while the experience-earnings and the tenure-earnings profiles are steeper in the private sector. The second of these results is in contradiction to that reported by Lindauer and Sabot (1983) for Tanzania but is consistent with that reported by Van der Gaag and Vijverberg (1988) for Cote d'Ivoire. The industry dummies are not significant in either wage equation with the exception that for the food and beverages industries for which wages are significantly lower for comparable workers in the private sector. Somewhat surprisingly, women on average earn less than otherwise comparable men in the public sector, while it is not evident that there is gender wage differential in the private sector. Location is also a significant influence on public sector earnings while wages in the private sector do not appear to vary between the capital city and regional towns. Wages do vary by occupation in both sectors, professional and technical workers always earning higher than workers of otherwise similar characteristics in other occupations. Non-professional administrative and clerical workers also seem to enjoy a wage premium in the public sector, which is not the case in the private sector.

Estimates of conditional wage equations corresponding to the job queue model are reported in Table 3.7, which shows that the OLS estimates of the wage equations of both sectors are subject to significant bias arising from selfselectivity or employer selectivity. Both selectivity terms are significant in the adjusted public sector conditional wage equation. And, although there is no evidence of self-selectivity bias in the OLS estimates of the private sector wage equation, employer-selectivity bias is evident. The null of no selectivity bias is rejected for each equation at the five per cent level of significance. Despite the bias in the unadjusted least square estimates the signs of the same estimates are reproduced in those of the adjusted estimates. The main implication of selectivity bias is that the rate of return to human capital in general and education in particular is grossly overestimated by OLS squares 
Table 6: OLS Estimates of Sectoral Wage Equations, Public and Private Sectors.

\begin{tabular}{|c|c|c|c|c|}
\hline \multirow[t]{2}{*}{ Variable } & \multicolumn{2}{|c|}{ Public Sector } & \multicolumn{2}{|c|}{ Private Sector } \\
\hline & Coefficient & Standard Error & Coefficient & Standard Error \\
\hline Constant & -1.0185 & 0.1052 & -0.9417 & 0.1477 \\
\hline EDUC & 0.0855 & 0.0072 & 0.0740 & 0.0110 \\
\hline EXPR & 0.0185 & 0.0066 & 0.01749 & 0.0097 \\
\hline EXPRSQ & -0.0003 & 0.0001 & -0.0001 & 0.0002 \\
\hline TENURE & 0.0253 & 0.0079 & 0.0508 & 0.0157 \\
\hline TENURESQ & -0.0001 & 0.0003 & -0.0008 & 0.0005 \\
\hline GENDER & 0.0813 & 0.0436 & -0.0709 & 0.0994 \\
\hline PROFTECH & 0.4704 & 0.0551 & 0.5207 & 0.1408 \\
\hline ADMCLER & 0.2295 & 0.0562 & 0.1195 & 0.1251 \\
\hline FOODBEV & -0.0797 & 0.1001 & -0.5056 & 0.2177 \\
\hline OTHMANU & -0.0176 & 0.060 & -0.0521 & 0.1125 \\
\hline OTHINDUS & 0.1292 & 0.0809 & 0.0791 & 0.1140 \\
\hline NONADDIS & 0.0978 & 0.04192 & 0.0623 & 0.1128 \\
\hline $\mathrm{R}^{2}$ & 0.48 & & 0.27 & \\
\hline Adj. $R^{2}$ & 0.47 & & 0.25 & \\
\hline Number of observations & 739 & & 431 & \\
\hline
\end{tabular}


estimates.

The estimated value of the proportion of private sector workers who have been rationed out of the public sector is 0.849 . It is therefore not surprising that the no-queue model is rejected by the J-test. However, I cannot reject the universal-queue model on the basis of the same test. Indeed, estimates of the conditional wage equation of either sector obtained under the queue model and as reported in Table 3.7 are practically the same as those obtained under the restriction of a universal job-queue (Table 3.10). On the other hand, estimates obtained under the no-queue model (Table 3.8) are fairly close to the unadjusted least squares estimates for either sector. It is important to note that the selectivity regressors used in the estimation of the conditional wage equations under the alternative no-queue and universalqueue restrictions as reported in Tables 3.8 and 3.10 are based on estimates of the reduced form parameters of the general bivariate specification of the switching probit as reported in Table 3.2. Some loss of efficiency is therefore bound to result in either case should the no-queue or the universal-queue models be in fact correct. If the no-queue model were not rejected more efficient estimates of the coefficients of the unconditional wage equations would be provided by Table 3.9. Likewise if the simple probit universal queue specification were not rejected more efficient estimates of the coefficients of the unconditional wage equations would be provided by columns Table 3.11.

The selectivity bias of OLS estimates of coefficients of the unconditional sectoral wage functions naturally translates to a bias in the OLS estimate of the pure sectoral mean wage differential. Following Gyourko and Tracy (1988) I distinguish between the unconditional and the conditional pure mean wage differentials. The first of these is the mean of expected earnings differentials on which workers base their sector preference. It therefore disregards selection effects in the determination of actual or conditional wages. The conditional mean differential in contrast is based on the relative earning position of a worker once the sector of employment of the worker has been determined. It differs from the unconditional mean differential in as far as selection effects are due to differences in rates of return to unobservable worker characteristics rather than due to differences in levels of the same characteristics. Let $\bar{X}$ be the population mean vector of observed worker and industry characteristics. Since I am assuming that wages are distributed log normal the unconditional mean wage differential is given by

$$
D I F_{1}=\exp \left[\bar{X}^{\prime}\left(\beta_{1}-\beta_{2}\right)+\frac{1}{2}\left(\sigma_{v_{1}}^{2}-\sigma_{v_{2}}^{2}\right)\right]-1
$$


Table 7: Selectivity Adjusted Least Squares Estimates of Sectoral Wage Equations, Job Queue Model.

\begin{tabular}{lllll}
\hline \multirow{2}{*}{ Variable } & \multicolumn{2}{l}{ Public Sector } & \multicolumn{2}{l}{ Private Sector } \\
\cline { 2 - 5 } & Coefficient & Standard Error & Coefficient & Standard Error \\
\hline Constant & -0.69 & 0.1783 & -0.7146 & 0.4136 \\
EDUC & 0.0689 & 0.0094 & 0.0030 & 0.0217 \\
EXPR & 0.0175 & 0.0066 & 0.0233 & 0.0107 \\
EXPRSQ & -0.0005 & 0.0002 & -0.0010 & 0.0003 \\
TENURE & 0.0152 & 0.01 & 0.0154 & 0.0255 \\
TENURESQ & 0.0003 & 0.0003 & -0.0006 & 0.0006 \\
GENDER & 0.1221 & 0.0479 & 0.1839 & 0.1240 \\
PROFTECH & 0.4226 & 0.0573 & 0.2011 & 0.1589 \\
ADMCLER & 0.2015 & 0.0575 & 0.0473 & 0.1253 \\
FOODBEV & -0.1445 & 0.1020 & -0.6211 & 0.2191 \\
OTHMANU & -0.0182 & 0.0613 & 0.2229 & 0.1398 \\
OTHINDUS & 0.0698 & 0.0904 & 0.1224 & 0.1413 \\
NONADDIS & 0.1255 & 0.0528 & -0.0656 & 0.1436 \\
& & & & \\
$\sigma_{1 v_{1}}$ & 0.2835 & 0.1619 & & \\
$\sigma_{1 v_{2}}$ & & & 0.0551 & 0.1789 \\
$\sigma_{2 v_{1}}$ & -0.2832 & 0.1153 & & \\
$\delta_{1}$ & & & 0.0468 & 0.2490 \\
$\delta_{2}$ & & & -0.5498 & 0.1463 \\
$\mathrm{R}^{2}$ & & & & \\
Adj. R & 0.48 & & 0.30 & \\
Number of observations & 739 & & 0.27 & \\
\hline
\end{tabular}


Table 8: Selectivity Adjusted Least Squares Estimates of Sectoral Wage Equations, No-queue Restrictions with Bivariate Sorting Probit.

\begin{tabular}{lllll}
\hline Variable & \multicolumn{2}{l}{ Public Sector } & \multicolumn{2}{l}{ Private Sector } \\
\cline { 2 - 5 } & Coefficient & Standard Error & Coefficient & Standard Error \\
\hline Constant & -1.0429 & 0.1061 & -0.5332 & 0.2776 \\
EDUC & 0.08376 & 0.0072 & 0.0733 & 0.0109 \\
EXPR & 0.0186 & 0.0066 & 0.0133 & 0.01 \\
EXPRSQ & -0.0004 & 0.0002 & -0.0002 & 0.0002 \\
TENURE & 0.0292 & 0.0082 & 0.0587 & 0.0163 \\
TENURESQ & -0.0001 & 0.0003 & -0.0009 & 0.0005 \\
GENDER & 0.0737 & 0.0438 & -0.0962 & 0.1002 \\
PROFTECH & 0.4493 & 0.0564 & 0.4867 & 0.1418 \\
ADMCLER & 0.2074 & 0.0577 & 0.008 & 0.1269 \\
FOODBEV & -0.1058 & 0.1012 & -0.5868 & 0.2222 \\
OTHMANU & -0.0372 & 0.0610 & -0.0908 & 0.1144 \\
OTHINDUS & 0.061 & 0.0906 & -0.0449 & 0.1343 \\
NONADDIS & 0.1494 & 0.0521 & 0.1952 & 0.1279 \\
& & & & \\
$\sigma_{1 v_{1}}$ & 0.2691 & 0.1624 & & \\
$\sigma_{1 v_{2}}$ & & & 0.1979 & 0.1140 \\
$\mathrm{R}^{2}$ & & & & \\
Adj. $\mathrm{R}^{2}$ & 0.48 & & 0.27 & \\
Number of observations & 739 & & 0.25 & \\
\hline
\end{tabular}


Table 9: Selectivity Adjusted Least Squares Estimates of Sectoral Wage Equations, No-queue Model, Univariate Sorting Probit.

\begin{tabular}{lllll}
\hline Variable & \multicolumn{2}{l}{ Public Sector } & \multicolumn{2}{l}{ Private Sector } \\
\cline { 2 - 5 } & Coefficient & Standard Error & Coefficient & Standard Error \\
\hline Constant & -1.3301 & 0.2446 & -0.9378 & 0.1480 \\
EDUC & 0.096 & 0.0103 & 0.0814 & 0.0186 \\
EXPR & 0.0213 & 0.0069 & 0.0198 & 0.0108 \\
EXPRSQ & -0.0004 & 0.0001 & -0.0002 & 0.0002 \\
TENURE & 0.0386 & 0.0123 & 0.0603 & 0.0249 \\
TENURESQ & -0.0004 & 0.0003 & -0.001 & 0.0007 \\
GENDER & 0.0341 & 0.0549 & -0.1089 & 0.1262 \\
PROFTECH & 0.476 & 0.0552 & 0.5419 & 0.1474 \\
ADMCLER & 0.2184 & 0.0567 & 0.1160 & 0.1254 \\
FOODBEV & -0.0672 & 0.1004 & -0.5112 & 0.2182 \\
OTHMANU & -0.0389 & 0.0618 & -0.0755 & 0.1222 \\
OTHINDUS & 0.0782 & 0.0885 & 0.04715 & 0.1314 \\
NONADDIS & 0.1539 & 0.0578 & 0.1085 & 0.1395 \\
& & & & \\
$\sigma_{1 v_{1}}$ & 0.2276 & 0.1614 & & \\
$\sigma_{1 v_{2}}$ & & & -0.1263 & 0.2578 \\
$\mathrm{R}^{2}$ & & & & \\
Adj. R & 0.48 & & 0.27 & \\
Number of observations & 0.47 & & 0.25 & \\
\hline
\end{tabular}


Table 10: Selectivity Adjusted Least Squares Estimates of Sectoral Wage Equations, Universal-queue Restrictions with Bivariate Sorting Probit.

\begin{tabular}{lllll}
\hline \multirow{2}{*}{ Variable } & \multicolumn{2}{l}{ Public Sector } & Private Sector \\
\cline { 2 - 5 } & Coefficient & Standard Error & Coefficient & Standard Error \\
\hline Constant & -0.6734 & 0.1783 & -0.7137 & 0.1547 \\
EDUC & 0.0712 & 0.0093 & 0.0009 & 0.0205 \\
EXPR & 0.0174 & 0.0066 & 0.0234 & 0.0096 \\
EXPRSQ & -0.0004 & 0.0001 & -0.001 & 0.0003 \\
TENURE & 0.0114 & 0.0098 & -0.0187 & 0.0227 \\
TENURESQ & 0.0003 & 0.0003 & 0.0006 & 0.0006 \\
GENDER & 0.1288 & 0.0478 & 0.1959 & 0.1165 \\
PROFTECH & 0.4454 & 0.0559 & 0.1977 & 0.1582 \\
ADMCLER & 0.2248 & 0.056 & 0.0514 & 0.1238 \\
FOODBEV & -0.1161 & 0.1009 & -0.6105 & 0.2150 \\
OTHMANU & 0.0017 & 0.0603 & 0.2351 & 0.1299 \\
OTHINDUS & 0.1413 & 0.0808 & 0.1468 & 0.1130 \\
NONADDIS & 0.0721 & 0.0431 & -0.0891 & 0.1071 \\
& & & & \\
$\sigma_{2 v_{1}}$ & -0.2759 & 0.1153 & & \\
$\sigma_{2 v_{2}}$ & & & -0.5658 & 0.1353 \\
$\mathrm{R}^{2}$ & & & & \\
Adj. ${ }^{2}$ & 0.48 & & 0.30 & \\
Number of observations & 0.47 & & 0.28 & \\
\hline
\end{tabular}


Table 11: Selectivity Adjusted Least Squares Estimates of Sectoral Wage Equations, Universal Queue Model with Univariate Sorting Probit.

\begin{tabular}{lllll}
\hline Variable & \multicolumn{2}{l}{ Public Sector } & \multicolumn{2}{l}{ Private Sector } \\
\cline { 2 - 5 } & Coefficient & Standard Error & Coefficient & Standard Error \\
\hline Constant & -2.089 & 0.3008 & -0.9224 & 0.1488 \\
EDUC & 0.1210 & 0.0117 & 0.1031 & 0.0303 \\
EXPR & 0.0286 & 0.0071 & 0.0259 & 0.0127 \\
EXPRSQ & -0.0005 & 0.0001 & -0.0003 & 0.0002 \\
TENURE & 0.0704 & 0.0142 & 0.0881 & 0.0395 \\
TENURESQ & -0.0011 & 0.0004 & -0.0016 & 0.0009 \\
GENDER & -0.0805 & 0.0607 & -0.2187 & 0.1747 \\
PROFTECH & 0.4918 & 0.0549 & 0.6025 & 0.1616 \\
ADMCLER & 0.1974 & 0.0563 & 0.0965 & 0.1271 \\
FOODBEV & -0.0546 & 0.0993 & -0.5022 & 0.2177 \\
OTHMANU & -0.0883 & 0.0623 & -0.1461 & 0.1449 \\
OTHINDUS & -0.0469 & 0.0926 & -0.0437 & 0.1650 \\
NONADDIS & 0.2920 & 0.0659 & 0.2372 & 0.1986 \\
& & & & \\
$\sigma_{2 v_{1}}$ & -0.7614 & 0.2007 & & \\
$\sigma_{2 v_{2}}$ & & & -0.4834 & 0.4698 \\
$\mathrm{R}^{2}$ & & & & \\
Adj. $\mathrm{R}^{2}$ & 0.49 & & 0.27 & \\
Number of observations & 0.48 & & 0.25 & \\
\hline
\end{tabular}


Table 12: Estimates of the Mean Public Sector Wage Premium Under Alternative Assumptions About Sample Selection.

\begin{tabular}{l|ll}
\hline Model & \multicolumn{3}{|l}{ Mean Public Sector Wage Premium (\%) } \\
\cline { 2 - 3 } & Unconditional & Conditional \\
\hline No Sample Selection & -21.4 & \\
Job Queue Model & 39.2 & 10.9 \\
No queue Model & -40.1 & -20.1 \\
& & \\
Universal Queue Model & 64.9 & 14.2 \\
\hline
\end{tabular}

To obtain the corresponding conditional differential we add terms of selection effects evaluated at the population mean to the bracketed terms of equation 3.1. Thus the expression for the conditional mean wage differential of the queue model is

$$
\begin{aligned}
D I F_{2}= & \exp \left[\bar{X}^{\prime}\left(\beta_{1}-\beta_{2}\right)+\frac{1}{2}\left(\sigma_{v_{1}}^{2}-\sigma_{v_{2}}^{2}\right)+\sigma_{1 v_{1}} \bar{\lambda}_{1}+\sigma_{2 v_{2}} \bar{\lambda}_{2}\right. \\
& \left.-\left(\sigma_{1 v_{2}} \bar{\lambda}_{3}+\delta_{1} \bar{\lambda}_{1}^{*}+\delta_{2} \bar{\lambda}_{4}\right)\right]-1
\end{aligned}
$$

where $\bar{\lambda}_{j}$ is the population mean of $\lambda_{j i}, j=1, \ldots, 4$ and $\bar{\lambda}_{1}^{*}$ is the population mean of $\lambda_{1 i}^{*}$.

The queue model implies that the unconditional mean wage of the public sector is nearly 1.4 times the unconditional mean wage of the private sector (Table 3.12). However, the conditional mean public sector wage premium is much lower at 11 per cent. Both differentials sharply contrast with the 21 per cent unconditional mean private sector wage premium we would get if we suppressed the problem of sample selection altogether. The no-queue model actually magnifies the bias in the estimated mean differential implying a private sector unconditional premium of more than 40 per cent and conditional premium of 20 per cent. As is to be expected the mean wage differential obtained under the universal queue restriction is quite close to that of the general model implying a public sector unconditional premium of 65 per cent and conditional premium of 14.2 per cent. 


\subsection{Estimates of Structural IQ and CFQ Probits}

Maximum likelihood estimates of the structural sorting probits of the queue model are presented in Table 3.13 while those of the no-queue and universal queue models are given in Table 3.14. The most remarkable of the results of the estimation of the no-queue model is that the public versus private sector wage differential is not a significant influence on the sectoral choice of workers. A similar result is reported by Van der Gaag and Vijverberg (1987) who estimated the same model for Cote d'Ivoire. Van der Gaag and Vijverberg seem to explain their finding as a consequence of non-wage benefits being a high proportion of the compensation package of public sector workers. Gill (1988) reports a similar result in a slightly different context and argues that the finding may be because contemporaneous wage differentials poorly proxy for expected lifetime earning differentials. My estimates of the queue model point to a more immediate explanation than either of these: that the no-queue model is a misspecification of the actual sorting mechanism. According to the estimated queue model the public-private wage differential is, in fact, 'the single most important factor' in the determination of workers' sector preferences. We do not read the same result from the estimation of the no-queue model simply because the procedure leads to biased estimates of the differential. Parameter estimates of the universal queue model are broadly similar to those of CFQ function of the queue model. However, by construction the universal queue model implies that worker preferences and, hence, sectoral wage differentials, play no part in the allocation of workers between the two sectors. This is a restriction on the queue model that we were unable to reject on the basis of the J-test for a queue. However, we have rejected the same restriction based on Abowd and Farber's test applied to the reduced form sorting probits. Abowd and Farber's test for a job queue can also conducted on the basis of estimates of the structural probits and again leads to a rejection of the universal queue model in favour of the queue model. The log likelihood of the universal queue model is -572.2 which compares to a $\log$-likelihood of -528.4 for the queue model.

Focusing on parameter estimates of the queue model, we see from Table 3.13 that, once we control for expected sectoral wage differentials, family background as indicated by paternal employment status is the strongest influence on a worker's desire for a public sector job. It is followed by gender, location of residence and human capital in that order of importance. From the recruitment point of view, the wage a worker would command as a public 
Table 13: Maximum Likelihood Estimates of Structural Parameters of the Job Queue Model.

\begin{tabular}{|c|c|c|c|c|}
\hline \multirow[t]{2}{*}{ Variable } & \multicolumn{2}{|c|}{ IQ Function } & \multicolumn{2}{|c|}{ CFQ Function } \\
\hline & Coefficient & Standard Error & Coefficient & Standard Error \\
\hline Constant & -1.7141 & 0.2455 & -0.5566 & 0.9793 \\
\hline $\ln \widehat{W}_{1 i}-\ln \widehat{W}_{2 i}$ & 1.1044 & 0.4346 & & \\
\hline$X_{i} \widehat{\beta}_{1}+\widehat{\sigma}_{1 v_{1}} \hat{\lambda}_{1 i}$ & & & -4.1109 & 1.0206 \\
\hline EDUC & -0.04623 & 0.0783 & 0.3537 & 0.0930 \\
\hline EDUCSQ & 0.0098 & 0.0050 & -0.0053 & 0.0038 \\
\hline EXPR & 0.0298 & 0.0275 & 0.0311 & 0.0368 \\
\hline EXPRSQ & 0.0002 & 0.0009 & -0.0020 & 0.0006 \\
\hline TENURE & 0.1346 & 0.0322 & 0.0659 & 0.0380 \\
\hline TENURESQ & -0.0036 & 0.0014 & 0.0015 & 0.0011 \\
\hline GENDER & -0.6045 & 0.1464 & 0.4664 & 0.2615 \\
\hline FATPRWAG & -0.6875 & 0.2321 & & \\
\hline FATPUWAG & -0.080 & 0.1632 & & \\
\hline FATOWNAC & -0.3314 & 0.1902 & & \\
\hline ADMCLER & -0.1840 & 0.2057 & 0.7205 & 0.3864 \\
\hline PROFTECH & 0.2125 & 0.2275 & 1.7124 & 0.5225 \\
\hline NONADDIS & 0.2317 & 0.1601 & 0.9504 & 0.2118 \\
\hline Log likelihood & & & & \\
\hline Number of obser & & & & \\
\hline
\end{tabular}


Table 14: Maximum Likelihood Estimates of the Structural Parameters of the No-queue and Universal Queue Models.

\begin{tabular}{lllll}
\hline Variable & \multicolumn{2}{l}{ No-queue Model } & \multicolumn{2}{l}{ Univeral-queue Model } \\
\cline { 2 - 5 } & Coefficient & Standard Error & Coefficient & Standard Error \\
\hline Constant & -1.4755 & 0.2597 & 7.1782 & 2.6327 \\
$\widetilde{\ln }_{1 i}-\ln W_{2 i}$ & 0.0784 & 0.4714 & & \\
$\widetilde{\ln }_{1 i}$ & & & -4.1765 & 1.2475 \\
EDUC & 0.1663 & 0.0388 & -0.3381 & 0.1526 \\
EDUCSQ & -0.0037 & 0.0022 & -0.0040 & 0.0022 \\
EXPR & 0.0206 & 0.0118 & -0.0925 & 0.0370 \\
EXPRSQ & -0.0003 & 0.0002 & 0.0016 & 0.0006 \\
TENURE & 0.1326 & 0.0186 & -0.1607 & 0.0883 \\
TENURESQ & 0.0030 & 0.0006 & 0.0017 & 0.0015 \\
GENDER & -0.5798 & 0.1152 & -0.2022 & 0.1390 \\
FATPRWAG & -0.8153 & 0.1827 & & \\
FATPUWAG & 0.0354 & 0.1206 & & \\
FATOWNAC & -0.1829 & 0.1314 & & \\
ADMCLER & -0.3670 & 0.1293 & -0.8959 & 0.2861 \\
PROFTECH & 0.2752 & 0.1326 & -1.8320 & 0.6359 \\
NONADDIS & 0.6298 & 0.0990 & -0.5672 & 0.3742 \\
Log likelihood & -568.65 & & -574.73 & \\
Number of observations & 1170 & & 1170 & \\
\hline
\end{tabular}


sector employee is the most important determinant of the likelihood of the worker being selected from the queue for public sector jobs: given the public sector's recruitment policy, workers on the lower end of the pay scale are more likely to be selected. This further supports the hypothesis that public sector employers are cost minimisers, a result already suggested by the reduced form marginal effects of skill variables on CFQ probabilities.

In Tables 3.15 to 3.16 I report estimates of the average IQ probabilities of the base group at various levels of schooling and market experience. A comparison of these with Tables 3.4 and 3.5 shows that the higher average IQ probabilities of higher skill groups are basically a result of a positive correlation between skill and expected sectoral wage differential. In the absence of a positive public sector wage premium, the probability that a worker of any skill group prefers public sector employment is negligible except at extremely high levels of schooling or experience. On the other hand, due to a strong positive correlation between skill and public sector wage rates, the average reduced form CFQ probability of a high skill group underestimates the corresponding structural probability. To the extent more skilled workers command higher wages, they are less attractive to cost minimising employers. To the extent that higher skill means higher productivity, the likelihood of being selected from a job queue increases with skill. The average CFQ probability of a high skill group that we calculate by fixing the public sector wage at a rate that is uniform across skill groups must therefore be higher than the average probability we obtain on the basis of estimates of the reduced form CFQ function, in which we cannot control for variation in the cost of employment. That said, we should note that the basic implication of the reduced form sorting mechanism that the IQ probability decreases or is invariant with skill while the CFQ probability increases with the same, is confirmed by estimates of the structural probits. This we can see from Tables 3.15 and 3.16, where the marginal effects of education and market experience on the IQ probability are not statistically different from zero except at the extreme schooling or experience levels. In contrast, the marginal effects of the same variables on the CFQ probability are positive, significant and generally increasing.

Another major point of difference between the information content of the reduced form and structural sorting probits of the queue model concerns the role of gender in the IQ and CFQ functions. As pointed out earlier, my estimates of reduced form parameters imply that although women are no more likely to prefer public sector employment than men, they have a greater 
Table 15: Probabilities of IQ and CFQ Status as Functions of Schooling, Structural Job Queue Model.

\begin{tabular}{l|ll|ll} 
& \multicolumn{3}{l}{ (Standard errors in parentheses) } \\
\hline \multirow{2}{*}{$\begin{array}{l}\text { Schooling } \\
\text { (years) }\end{array}$} & IQ at Zero Expected Wage Premium & \multicolumn{2}{l}{ CFQ at Mean Public Sector Wage } \\
\cline { 2 - 5 } & Probability & Marginal Effect & Probability & Marginal Effect \\
\hline 0 & 0.0102 & -0.0013 & 0.0094 & 0.0089 \\
& $(0.0074)$ & $(0.0025)$ & $(0.0331)$ & $(0.0260)$ \\
6 & 0.0125 & 0.0023 & 0.3379 & 0.1062 \\
8 & $(0.0103)$ & $(0.0024)$ & $(0.3550)$ & $(0.0313)$ \\
& 0.0197 & 0.0053 & 0.5564 & 0.1064 \\
12 & $(0.0167)$ & $(0.0047)$ & $(0.3423)$ & $(0.0405)$ \\
16 & 0.0197 & 0.0091 & 0.8719 & 0.0476 \\
& $(0.0193)$ & $(0.0089)$ & $(0.1440)$ & $(0.0475)$ \\
& 0.2934 & 0.0923 & 0.9750 & 0.0108 \\
& $(0.1938)$ & $(0.0563)$ & $(0.0370)$ & $(0.0139)$ \\
\hline
\end{tabular}

* Base group characteristics: a male worker residing in the capital with no market experience, no current job tenure, a traditional farmer as a father and employed in a non-professional, non-technical job in the service industry 
Table 16: Probabilities of IQ and CFQ Status as Functions of Market Experience, Structural Job Queue Model.

\begin{tabular}{l|ll|ll}
\hline \multirow{3}{*}{$\begin{array}{l}\text { Experience } \\
\text { (years) }\end{array}$} & \multicolumn{3}{l}{ (Standard errors in parentheses) } & \multicolumn{3}{l}{} \\
\cline { 2 - 5 } & IQ at Zero Expected Wage Premium & \multicolumn{2}{l}{ CFQ at Mean Public Sector Wage } \\
\hline 0 & 0.0262 & 0.0018 & Probability & Marginal Effect \\
\hline 5 & $(0.0220)$ & $(0.0013)$ & 0.6576 & 0.0091 \\
& 0.0371 & 0.0026 & $(0.3001)$ & $(0.0077)$ \\
10 & $(0.0245)$ & $(0.0017)$ & 0.6953 & 0.0107 \\
& 0.0525 & 0.0036 & $(0.2481)$ & $(0.0067)$ \\
15 & $(0.0307)$ & $(0.0022)$ & 0.6966 & 0.0124 \\
& 0.0525 & 0.0038 & $(0.2209)$ & $(0.0053)$ \\
20 & $(0.0317)$ & $(0.0025)$ & 0.6966 & 0.0131 \\
& 0.0964 & 0.0065 & $(0.2027)$ & $0.0047)$ \\
& $(0.0574)$ & $(0.0041)$ & 0.7334 & 0.0150 \\
& & & $(0.1874)$ & $(0.0062)$ \\
\hline
\end{tabular}

* Base group characteristics: a male worker residing in the capital with 9 years of schooling, no current job tenure, a traditional farmer as a father and employed in a non-professional, non-technical job in the services industry 
probability of being selected from the public sector job queue. According to the first column of Table 3.13 this is the case only because we fail to control for the influence of wage differentials on sector preferences in estimating the reduced form sorting mechanism. The estimates of the structural parameters of the same mechanism reveal that, for a given sectoral wage differential, women are, in fact more likely to choose public sector employment than men while, given the public sector wage rate, employers are more likely to select men than women from the public sector job queue. In other words, that women are not seen to have greater preference for public sector jobs from the reduced form estimates is a consequence of the fact that the public sector wage premium is lower in their case. Similarly, the reduced form estimates suggest that women have a higher probability of being selected from the public sector job queue only because the cost of employing a female worker is lower to public sector employers than the cost of employing an otherwise comparable male.

\section{Summary and Conclusion}

In this paper I have attempted to test and measure the existence and scope of a public sector job queue in Ethiopia's urban labour market. In order to carry out the test I have extended Lee's two stage structural probit analysis by replacing the univariate specification of the sorting probit by Poirier's probit with partial observablility. The results reject the absence of job rationing in favour of a partial queue for public sector jobs. The queue is largely due to the expectation of large public sector wage premiums the mean of which is estimated at 11 per cent if we ignore returns to unobservable worker characteristics and at the hefty figure of 40 per cent otherwise.

However, there is more to the length or the composition of the queue than the expectation of higher public sector wages. When I control for individual differences in the expected public sector wage premium, family background as indicated by the main sector of employment of the father of a worker is the most important influence on the worker's sector preference. Specifically, a worker with a traditional farming family background is more likely to be in the queue than a worker who is at least a second generation urban dweller. This is significant in view of the recent nature of urbanisation in Ethiopia even by African standards. It seems to suggest that the large influx of rural migrants to urban centres observed in the last two to three decades in the 
country is at least in part fuelled by anticipated public sector employment. Gender and location of residence relative to Addis Ababa, as the political capital and by far the largest urban economy in the country, are next in importance as the determinants of sector preference. On average, women are more likely than men to prefer public sector jobs while a worker in a provincial town is more likely to be in the queue for the same jobs than a worker based in the capital. On the other hand, I find that skill as indicated by levels of schooling and market experience is not a significant influence on the sector preference of a worker once we control for individual differences in earning potential in either sector.

On the recruitment side, I find that the probability of a worker being selected from the a public sector job queue decreases with the wage rate the worker potentially commands as a public sector employee. Given the public sector's pay rules and the composition of workers in terms of observable characteristics, workers on the lower end of the pay scale are more likely to be selected. This is consistent with public sector employers making cost minimising recruitment decisions. The hypothesis of cost minimising public sector employers is further supported by the result that, although the queuing status of workers is independent of skill, more skilled workers are more likely to be chosen once in the queue. However, I also find that women are less likely to be selected than men of comparable observable characteristics.

None of these results can be read directly from the estimation of the reduced form sorting probits as was done for instance in Abowd and Farber(1982). This is because reduced form parameters fail to distinguish between the direct marginal effect of a variable on the probability of a worker being in the queue or being selected from it from the indirect marginal effect of the variable on the same probability through the variable's effect on expected wage rates in either sector. Thus although my estimates of the structural probits suggest skill is not a factor in the determination of the queuing status of a worker, the reduced form estimates imply that the marginal effect of skill on the probability of being in the queue is, in fact, significant and negative at higher levels of skill. At the same time the reduced form marginal effect of skill on the probability of being selected from the queue is larger than the structural marginal effect. The first of these suggests that the expected public sector wage premium decreases with the skill of a worker. The second suggests that the existing public sector pay structure lowers the relative price of higher skill grades for public sector employers inducing them to 'substitute skill for numbers'. The reduced form estimates also suggest 
that women are no more likely to be in the pubic sector queue than men but are more likely to be selected from the queue. Given the results of the estimation of the structural probit on the matter as reported above, this implies that women expect a lower public sector wage premium.

The rejection of the no-queue model implies that a univariate sorting probit would be a misspecification of the allocation of workers between the public and private sectors of Ethiopia's urban labour market. It is, of course, true that if a sorting mechanism can be accurately described by Poirier's probit, then it is also accurately described by a univariate probit. However, in the presence of a job queue, a univariate probit specification of the switch between wage regimes results in biased estimates of the expected sectoral wage differential. This in turn leads to a biased estimate of the coefficient of the public sector wage premium in the structural probit. It is not therefore surprising that some studies based on the univariate specification have reported the result that sectoral wage differentials do not influence choice of sector, which is, indeed, the result that I also get by estimating the no-queue model. Although, several explanations can be put forward for this rather counter intuitive result, the estimation of both the queue and the no-queue models suggests a readier account of it.

\section{References}

[1] Abowd, J. M. and Farber, H.S. 1982. 'Job Queues and the Union Status of Workers.' Industrial and Labour Relations Review 35, 354-67.

[2] Ahn, S. C. 1992. 'The Lagrangian Multiplier Test for a Model with Two Selectivity Criteria.' Economics Letters 38, 9-15.

[3] Amemiya, T. 1974. 'Multiple Regression and Simultaneous Equation Models When the Dependent Variables are Truncated Normal.' Econometrica 42, 999-1012.

[4] Bjorklund, A. and Moffit, R. 1987. 'The Estimation of Wage Gains and Welfare Gains in Self-Selection Models.' The Review of Economics and Statistics $69,43-49$.

[5] Choudhury, S. 1994. 'New Evidence on Public Sector Wage Differentials.' Applied Economics 26, 259-266. 
[6] Davidson; R. and Mackinnon, J. G. 1981. 'Several Tests for Model Specification in the Presence of Alternative Hypotheses.' Econometrica 49, 781-703.

[7] Dustmann C. and Van Soest, A. 1995. 'Generalised Swiching Regression Analysis of Private and Public Sector Wage Structures in Germany.' Mimeo. University College London and Tilburg University.

[8] Farber, H. S. 1983. 'The Determination of the Union Status of Workers.' Econometrica 51, 1417-37.

[9] Gill, A.M. 1988. 'Choice of Employment Status and Wages of Employees and the Self-Employed: Some Further Evidence.' Journal of Applied Econometrics 3, 229-234.

[10] Gyourko, J. and Tracy, J. 1988. 'An Analysis of Public and Private Sector Wages Allowing For Endogenous Choices of Both Government and Union Status.' Journal of Labor Economics 6, 229-253.

[11] Ham, J. C. 1982. 'Estimation of a Labour Supply Model with Censoring Due to Unemployment and Underemployment.' Review of Economic Studies 49, 335-354.

[12] Hartog, J. and Oosterbeek, H. 1993. Public and Private Sector Wages in the Netherlands.' European Economic Review 37, 97-114.

[13] Heller, P. and Tait, A. 1994. 'Government Employment and Pay: Some International Comaprisons.' IMF Occasional Papers No. 24.

[14] Heywood J. S. and Mohanty, M. S. 1994. 'The Role of Employer and Workplace Size in the US Federal Sector Job Queue.' Oxford Bulletin of Economics and Statistics 56, 171-188.

[15] Hundley, G. 1991. 'Public and Private Sector Occupational Pay Structures.' Industrial Relations 30, 417-434.

[16] Krueger, A.B. 1988. 'The Determinants of Queues for Federal Jobs.' Industrial and Labour Relations Review 41, 567-581.

[17] Lee, L.F. 1978. 'Unionism and Wage Rates: A Simultaneous Equations Model With Qualitative and Limited Dependent Variables.' International Economic Review 19, 415-33. 
[18] 1979. 'Identification and Estimation in Binary Choice Models With Limited (Censored) 'Dependent Variables.' Econometrica 47, 97796.

[19] —-, Maddala, G. S. and Trost, R. P. 1980. 'Asymptotic Covariance Matrices of Two-Stage Probit and Two-Stage Tobit Methods for Simultaneous Equation Models with Selectivity.' Econometrica 48, 491-503.

[20] Lindauer, D.L. 1991. 'Government Pay and Employment Policy: A Parallel Market in Labour.' in M. Roemer and C. Jones (eds.), Markets in Developing Countries: Parallel, Fragmented and Black. ICS Press: San Francisco.

[21] — and Sabot, R. H. 1983. 'The Public-Private Sector Wage Differential in a Poor Urban Economy.' Journal of Development Economics 12, 137-153.

[22] Maddala, G. S.1983. Limited Dependent and Qualitative Variables in Econometrics. Cambridge University Press: Cambridge.

[23] Pedersen, J.B. et. al. 1990. 'Wage Differerntials Between the Public and Private Sectors.' Journal of Public Economics 41, 125-145.

[24] Poirier, D. J. 1980. 'Partial Observability in Bivariate Probit Models.' Journal of Econometrics 12, 209-17.

[25] Rees, H. and Shah, H. 1986. 'An Empirical Analysis of Self-Employement in the UK.' Journal of Applied Econometrics 1, 95-108.

[26] Robinson, C. and Tomes, N. 1984. 'Union Wage Differentials in the Public and Private Sectors: A Simultaneous Equations Specification.' Journal of Labour Economics 2, 106-27.

[27] Shapiro, D.M. and Stelcner, M. 1989. 'Canadian Public-private Sector Earnings Differencials, 1970-1980.' Industrial Relations 28, 73-81.

[28] Stevenson, G. 1992. 'How Public Sector Pay and Employment Affect Labour Markets.' World Bank Policy Research Working Paper No. 944.

[29] Tallis, G. M. 1961. 'The Moment Generating Function of the Truncated Multinormal Distribution.' Journal of the Royal Statistical Society Series B 23, 223-29. 
[30] Terrel, K. 1993. 'Public-Private Wge Differentials in Haiti: Do Public Serevants Earn Rent?' Journal of Development Economics 42, 293-314.

[31] Upadhyay, M. P. 1997. 'Can Public Sector Employment Spur Human Capital Acquision?' Economics Letters 56, 121-127.

[32] Van der Gaag, J. and Vijverberg, W. 1988. 'A Switching Regression Model for Wage Determination in the Public and Private Sectors of a Developing Country.' The Review of Economics and Statistics 70, 224252.

[33] Van Ophem, H. 1993. 'A Modified Switching Regression Model ofEarnings Differentials Between the Public and Private Sectors in the Netherlands.' The Review of Economics and Statistics 75, 215-22:4.

[34] Venti, S.F. 1987. 'Wages in the Federal and Private Sectors.' in D. A. Wise (ed.), Public Sector Payrolls, University of Chicago Press: Chicago and London. 


\section{Policy Research Working Paper Series}

Thise

WPS2085 Monitoring Banking Sector Fragility:

A Multivariate Logit Approach with an Application to the 1996-97

Banking Crises

WPS2086 Deregulating Technology Transfer in Agriculture: Reform's Impact on Turkey in the 1980s

WPS2087 Male-Female Differences in Labor Market Outcomes during the Early Transition to Market: The Case of Estonia and Slovenia

WPS2088 Expropriation of Minority Shareholders: Evidence from East Asia

\section{WPS2089 Corporate Diversification in East Asia: The Role of Ultimate Ownership and Group Affilication

$\begin{aligned} & \text { WPS2090 Risks, Lessons Learned, and } \\ & \text { Secondary Markets for Greenhouse } \\ & \text { Gas Reductions }\end{aligned}$
WPS2091 Beyond Unequal Development:
An Overview

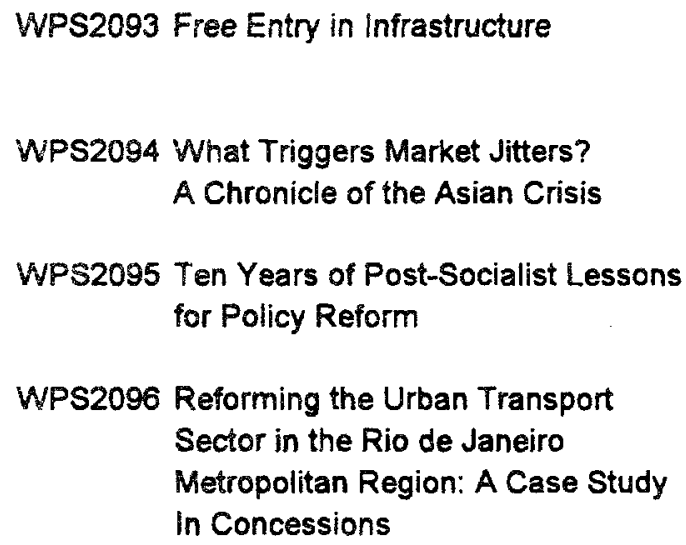

Author

Asli Demirgüç-Kunt

Enrica Detragiache

David Gisselquist

Carl Pray

Peter F. Orazem

Milan yodopivec

Stijn Claessens

Simeon Djankov

Joseph P. H. Fan

Larry $H$. P. Lang

Stijn Claessens

Simeon Djankov

Joseph P. H. Fan

Larry H. P. Lang

Donald F. Larson

Paul Parks

Andrés Solimano

Shantayanan Devarajan

Andrew Sunil Rajkumar

Vinaya Swaroop

David Ehrhardt

Rebecca Burdon

Graciela L. Kaminsky

Sergio L. Schmukler

Grzegorz W. Kolodko

Jorge M. Rebelo
Date

March 1999

March 1999

March 1999

March 1999

March 1999

March 1999

March 1999

March 1990

March 1999

April 1999

April 1999

April 1999
P. Kokila

33716

Contact for paper

K. Labrie 31001

L. Tabada 36896

S. Fallon 38009

R. Vo 33722

R. Vo 33722

A. Solimano 87671

C. Bernardo 31148

R. Bartolome 35703

S. Holt 37859

J. Prochnow-Waker 37466

A. Turner 30933 
Title

WPS2097 The Theory of Access Pricing: An Overview for Infrastructure Regulators

WPS2098 Reconsidering the Evidence on Returns to T\&V Extension in Kenya

WPS2099 Mutual Funds and Institutiona! investments: What is the Most Efficient Way to Set Up Individua! Accounts in a Social Security System?

WPS2100 Decentralization in Regional Fiscal Systems in Russia: Trends and Links to Economic Performanse

WPS2101 Are Wages and Productivity in Zimbabwe Affected by Human Capital Investment and International Trade?

WPS2102 Self-Employment and Labor Turnover: Cross-Country Evidence

WPS2103 Was Credit Channel a Key Monetary Hyun E. Kim Transmission Mechanism followirg the Recent Financial Crisis in the Republic of Korea?

WPS2104 The Relative Effecis of Skill Formation and Job Matching on Wage Growth in Ethiopia
Author

Date

April 1998

Anterio Estacha

Madin: Gautam

Jock R. Anderson

Estelle James

Gary Ferrier

James Smathout

Oimitri vittas

Lev Freinkman

Plemen Yossifov

Dorte Verner

William F. Maloney

April 1999

April 1999

April 1999

April 1999

April 1999

April 1999
Contas for paper

G. Chenet-Snith 36370

M. Gatitam 30442

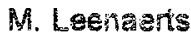
84254 Z. Nekaiefi-Nowrouz 39057

H. Vargas

37874

T. Gomez

32127

D. Peterson 32692

April 1999

A. Bonfield 31248

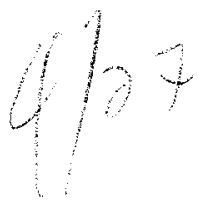

